\title{
Teriflunomide in multiple sclerosis: an update
}

\author{
Aaron E Miller*
}

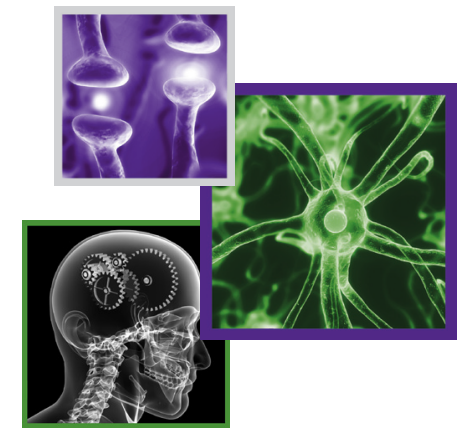

\section{Practice points}

Dosage \& administration

- Teriflunomide is a once-daily oral immunomodulator approved in the European Union (14 mg) for the treatment of relapsing-remitting multiple sclerosis (MS) and in the USA (7 and $14 \mathrm{mg}$ ) for the treatment of relapsing forms of MS.

Mechanism of action: immunomodulation

- Teriflunomide reversibly inhibits dihydroorotate dehydrogenase, a mitochondrial enzyme necessary for de novo pyrimidine synthesis.

- Dihydroorotate dehydrogenase inhibition limits the available pyrimidine pool for T- and B-cell proliferation, thereby decreasing the number of activated $T$ and $B$ cells available to cross the blood-brain barrier and enter the central nervous system.

- Immune responses are preserved during treatment with teriflunomide.

Pharmacodynamics, pharmacokinetics \& metabolism

- Oral bioavailability of teriflunomide is approximately $100 \%$.

- Pharmacokinetic characteristics of teriflunomide do not vary significantly with food intake, mild-to-moderate hepatic impairment, renal impairment, gender or age.

- Teriflunomide binds extensively to plasma protein (>99\%).

- Two accelerated elimination procedures have been shown to rapidly lower the plasma concentration of teriflunomide by $>98 \%$ over 11 days.

\section{Drug interactions}

- Exposure to drugs metabolized by CYP2B6, CYP2C8, CYP2C9, CYP2C19, CYP3A, OAT3, BCRP and OATP1B1/B3 transporters may be increased by teriflunomide.

- Ethinylestradiol and levonorgestrel exposure may be increased by teriflunomide.

- Exposure to drugs metabolized by CYP1A2 may be decreased by teriflunomide.

- Peak international normalized ratio in patients treated with warfarin may be decreased by teriflunomide.

- In patients receiving teriflunomide, rosuvastatin dosages should not exceed $10 \mathrm{mg}$ once daily or should be reduced by $50 \%$, in accordance with local guidelines.

- Cholestyramine or activated charcoal should not be used in patients treated with teriflunomide unless an accelerated elimination of teriflunomide is desired.

- Patients should be monitored and the doses of concomitant drugs adjusted accordingly.

\section{Clinical efficacy}

- Annualized relapse rates were significantly better with teriflunomide compared with placebo in two pivotal trials (TEMSO and TOWER). 
Practice points (cont.)

\section{Clinical efficacy (cont.)}

- Expanded Disability Status Scale scores were significantly improved with teriflunomide 14 mg versus placebo in two Phase III trials (TEMSO and TOPIC).

- Teriflunomide significantly reduced brain volume loss compared with placebo after 12 and 24 months in TEMSO when evaluated using standardized analysis of brain atrophy using the Structural Image Evaluation Using Normalization of Atrophy method.

- The efficacy of teriflunomide in patients with relapsing-remitting MS is also supported by supplementary measures such as predictions of disease outcomes with modified Rio score, number needed to treat and no evidence of disease activity.

- Efficacy of up to 9 and 5.5 years of teriflunomide treatment have been demonstrated in extensions of the TEMSO and TOWER trials, respectively.

- Significantly fewer patients receiving teriflunomide converted to clinically definite MS compared with those receiving placebo in a randomized, double-blind, placebo-controlled Phase III clinical trial of the efficacy of teriflunomide in patients with a first clinical episode suggestive of MS (TOPIC).

- Rate of relapse or treatment discontinuation was not significantly better with teriflunomide than with IFNB-1a in patients with relapsing forms of MS (TENERE).

\section{Safety \& tolerability}

- Teriflunomide has a well-characterized, manageable safety and tolerability profile that is consistent across studies and established with up to 12 years of exposure.

\section{KEYWORDS}

- clinical trials

- disease-modifying therapy

- drug development

- multiple sclerosis

- teriflunomide

Teriflunomide, a once-daily, oral disease-modifying therapy, has demonstrated efficacy in patients with relapsing forms of multiple sclerosis (MS) and patients with a first clinical episode suggestive of MS. As the only disease-modifying therapy with positive disability results in two Phase III trials, teriflunomide significantly slowed disability in patients with relapsing forms of MS. We highlight data from the Phase II study and the TEMSO, TOWER, TOPIC and TENERE teriflunomide studies. TEMSO MRI outcomes have been supported with Structural Image Evaluation Using Normalization of Atrophy analyses. We present data from long-term extensions of the Phase II study, TEMSO and TOWER, as well as results from patients who switched from other disease-modifying therapies to teriflunomide, patient-reported outcomes and supplementary measures of response.

First draft submitted: 28 June 2016; Accepted for publication: 14 November 2016; Published online: 15 December 2016.

Multiple sclerosis (MS), an autoimmune demyelinating disease, is one of the most common neurological diseases and the leading cause of nontrauma-related disability in young adults [1]. In approximately $85 \%$ of cases, the disease follows a relapsing-remitting course in which patients have episodes of relapse usually followed by improvements, with an overall tendency toward worsening disability and reduced cognitive function [1]. Relapsing-remitting MS (RRMS) often transitions to a phase called secondary progressive MS, in which symptoms gradually worsen or accumulate [2]. Approximately $10 \%$ of patients have a progressive disease course from the time of disease onset, known as primary progressive MS [1]. All forms of MS share the characteristic of a faster rate of brain atrophy relative to normal controls, which occurs even at the earliest stages of the disease [3].

In clinical trials, efficacy of MS treatments is typically assessed using annualized relapse rate (ARR) and disability worsening, although there is no direct link between relapses and long-term disability worsening $[4,5]$. Supplementary measures such as number needed to treat (NNT) [6], no evidence of disease activity (NEDA) [5], modified Rio (mRio) scoring [7] and patientreported outcomes [8], may help to provide a more complete picture of treatment effects. MRI 
assessments of disease activity, such as lesion numbers and volume, and brain atrophy, are also key indicators of MS disease activity, particularly as evidence supporting the association between brain atrophy and long-term disability has accumulated [9].

\section{Overview of currently available disease-modifying therapies}

- Injectable disease-modifying therapies

Injectable agents - interferons (IFNs) and glatiramer acetate (GA) - were the first disease-modifying therapies (DMTs) available for MS treatment. These therapies have been shown to reduce relapse frequency and MRI lesion development in patients with RRMS [10-13] and in patients with early MS [14-16], and the IFNs have also been shown to reduce the risk of disability in patients with RRMS. Although these agents are widely used, tolerability remains a concern; IFNs are associated with injection site reactions, flu-like symptoms and liver dysfunction, whereas GA is also associated with injection site reactions and transient systemic postinjection reactions [17].

In 2014, a pegylated form of IFN-beta (IFNB)-1a was approved. Pegylation increases the half-life, reducing dosing frequency thereby potentially improving overall tolerability [18]. A high-dose $(40 \mathrm{mg})$ formulation of GA, dosed three-times weekly instead of daily to improve convenience and adherence, was also approved in the USA in 2014 and in Europe in 2015 [19,20].

\section{- Oral DMTs}

Three oral DMTs - fingolimod (GILENYA ${ }^{\circledR}$, Novartis Pharmaceuticals Corp, NJ, USA), teriflunomide (AUBAGIO ${ }^{\circledR}$, Sanofi Genzyme, MA, USA) and dimethyl fumarate (DMF; TECFIDERA $^{\circledR}$, Biogen Inc, MA, USA) have been approved for treatment of RRMS. Fingolimod, the first oral therapy to be approved, is an oral sphinosine-1-phosphate receptor modulator that binds with high affinity to sphinosine-1-phosphate receptor and prevents lymphocyte egress from lymph nodes, thereby reducing auto-aggressive lymphocyte infiltration into the CNS [21]. In FREEDOMS (NCT00289978), once-daily fingolimod $0.5 \mathrm{mg}$ decreased ARR by $54 \%$ versus placebo $(\mathrm{p}<0.001)$ [22]. The proportion of patients with disability worsening confirmed for 12 weeks was lower with fingolimod $(17.7 \%, p=0.03)$ than placebo $(24.1 \%)$. Patients treated with fingolimod also had significantly fewer gadolinium (Gd)-enhancing lesions, fewer new/enlarged $\mathrm{T}_{2}$ lesions and smaller increases in $\mathrm{T}_{2}$ lesion volume than those in the placebo group (all p < 0.001) [22]. In FREEDOMS II (NCT00355134), a second placebo-controlled Phase III trial, a similar relative reduction in ARR versus placebo was observed (48\% reduction vs placebo) [23]. However, no significant effects of fingolimod on disability worsening were reported in FREEDOMS II [23]. When fingolimod treatment is initiated, patients should be closely monitored for cardiovascular events, such as bradyarrhythmia and atrioventricular block [24]. Patients should also be monitored for macular edema because of the increased risk associated with the treatment. Fingolimod may also increase the risk of infections. In the postmarketing setting, serious, life-threatening events of disseminated varicella zoster and herpes simplex infections, including one fatal event, have been reported with fingolimod treatment. At the time of publication, there had been five postmarketing reports of progressive multifocal leukoencephalopathy (PML) in patients receiving fingolimod who had not previously received natalizumab (NTZ) [25-28].

DMF is an oral DMT administered twicedaily to treat RRMS. Although its mechanism of action in MS is not fully understood, DMF is known to activate the nuclear factor (erythroidderived 2)-like 1 pathway, which is involved in the oxidative stress response [29]. In two Phase III clinical trials (CONFIRM [NCT00451451] and DEFINE [NCT00420212]), twice-daily DMF $240 \mathrm{mg}$ reduced ARRs by 44 and $53 \%$ versus placebo, respectively ( $p<0.001$ for both) [30,31]. In DEFINE, twice-daily DMF reduced the risk of disability worsening by $38 \%$ versus placebo ( $p=0.005$ ) [31]; however, reductions in disability worsening with DMF were not significant in CONFIRM [30]. DMF reduced the numbers of $\mathrm{Gd}$-enhancing lesions and new/enlarging $\mathrm{T}_{2}$ lesions versus placebo in both trials $(\mathrm{p}<0.001)$ [30,31]. Adverse events (AEs) commonly associated with DMF were flushing and gastrointestinal events; these typically dissipated after the first month of treatment [30,31]. In clinical trials, DMF treatment was associated with persistent lymphopenia in some patients, although persistent lymphopenia in DMF recipients was not associated with increased rates of infections or serious infections (vs placebo) [32]. Four patients treated with DMF in the postmarketing setting have now been reported to have 
developed PML, not always in the context of prolonged lymphopenia [33].

\section{- Monoclonal antibody therapies}

NTZ (TYSABRI ${ }^{\circledR}$, Biogen Idec Inc, MA, USA) was the first monoclonal antibody approved for MS treatment. NTZ targets very-late antigen $4,3 \alpha_{4} \beta_{1}$-integrin, CD49d/CD29 (VLA4) adhesion molecule, which plays a major role in the regulation of immune cell recruitment to sites of inflammation. Blockade of VLA4 prevents lymphocytes from crossing the blood-brain barrier and entering the CNS $[34,35]$. NTZ is administered intravenously (iv.) once every 4 weeks and is most often used in patients with highly active MS (frequent clinical relapses and/or MRI activity despite use of other DMTs). In AFFIRM (NCT00027300), a pivotal, randomized, double-blind Phase III trial, patients treated with NTZ for 2 years had a significantly reduced cumulative probability of disability worsening versus those who received placebo (17 vs $29 \%$, respectively; $\mathrm{p}<0.001$ ) [36]. ARR was lower in patients treated with NTZ versus placebo at 2 years ( 0.23 vs 0.73 , respectively; $p<0.001)$ [36]. Although NTZ is generally well tolerated, it is associated with an increased incidence of PML, a serious and potentially fatal brain infection caused by activation of the John Cunningham virus [37]. As of 7 September 2016, 682 cases of PML had been confirmed in patients with MS who had received NTZ [34].

Alemtuzumab (LEMTRADA ${ }^{\circledR}$, Sanofi Genzyme, MA, USA), the second monoclonal antibody approved for use in patients with MS, targets CD52 and depletes circulating $\mathrm{T}$ and $\mathrm{B}$ cells [38]. Within weeks of the initial depletion, lymphocytes begin to repopulate, which is thought to play a role in the therapeutic effect of alemtuzumab by rebalancing the dysfunctional immune system in MS [39]. Although the shift in the T-cell population might mediate the therapeutic effects of alemtuzumab, it has been proposed that the more rapid repopulation of $\mathrm{B}$ cells relative to $\mathrm{T}$ cells might contribute to the autoimmune AEs associated with alemtuzumab [40]. Alemtuzumab has a unique dosing regimen, administered via intravenous infusion on 5 consecutive days at baseline and on 3 consecutive days 12 months later. Alemtuzumab has been shown to reduce relapse rates and MRI disease activity versus IFNB-1a in treatment-naive patients and in patients who had relapsed on prior therapy $[41,42]$. In CARE-MS I (NCT00530348), a 2-year, pivotal, randomized Phase III trial in patients with active RRMS who were treatmentnaive, alemtuzumab significantly reduced the ARR compared with patients receiving IFNB-1a (0.18 vs 0.39 , respectively, $\mathrm{p}<0.0001$ ) [41]. In CARE-MS II (NCT00548405) alemtuzumab was evaluated in patients with active RRMS who relapsed on prior therapy. Similar to CARE-MS I, alemtuzumab treatment reduced ARR compared with IFNB-1a treatment $(0.26$ vs 0.52 , respectively; $\mathrm{p}<0.0001)$ and was also associated with significant reductions in 6-month confirmed disability worsening [42]. In both studies, alemtuzumab also demonstrated improvements in MRI outcomes, with greater proportions of patients free of Gd-enhancing lesions, new/enlarging $T_{2}$ lesions and new $T_{1}$ hypointense lesions after up to 4 years [43,44]. In addition, alemtuzumab-treated patients demonstrated a reduced rate of brain atrophy, as determined by median yearly percentage change in brain parenchymal fraction over 2 years [41,42]. Close safety monitoring is needed for patients treated with alemtuzumab because of concerns that include infusion-associated reactions and autoimmune events (such as thyroid disease, and, less frequently, immune thrombocytopenia and rare cases of antiglomerular basement membrane disease) [38].

Daclizumab (ZINBRYTATM, Biogen, MA, USA/AbbVie, IL, USA), the most recently approved treatment for adults with relapsing forms of MS, is a monoclonal antibody directed against CD25, the $\alpha$ subunit of the IL-2 receptor [45]. In the Phase II SELECT trial (NCT00390221), 1 year of daclizumab $150 \mathrm{mg}$ once-monthly led to significant reduction in ARR compared with placebo ( 0.21 vs 0.46 , respectively; $\mathrm{p}<0.0001$ ) and 52-week confirmed disability worsening (6 vs $13 \% ; \mathrm{p}=0.021$ ). Serious AEs, excluding MS relapse, occurred in 6 and $7 \%$ of patients in the placebo and daclizumab $150 \mathrm{mg}$ groups, respectively [46]. In DECIDE (NCT01064401), a Phase II, double-blind, active-controlled trial, treatment with daclizumab for up to 96 weeks significantly improved ARR compared with IFNB-1a ( 0.22 vs 0.39 , respectively; $\mathrm{p}<0.001)$. Numbers of new or newly enlarged $T_{2}$ hyperintense lesions were significantly reduced with daclizumab versus IFNB-1a (4.3 vs 9.4; $\mathrm{p}<0.001)$. Disability worsening confirmed for 12 weeks did not differ significantly between the treatment groups [47]. Serious AEs, excluding MS relapse, occurred in 
$15 \%$ of patients in the daclizumab group and $10 \%$ of patients in the IFNB-1a group [47].

\section{Introduction to teriflunomide}

Teriflunomide is a once-daily oral DMT, first approved in the USA in 2012, for the treatment of patients with relapsing forms of MS [48], and then subsequently for RRMS in other countries [49]. In core clinical trials and long-term extensions, teriflunomide treatment led to significant and consistent benefits on a range of clinical, MRI and disability markers of disease activity in several patient populations [50-53]. In addition, teriflunomide has a well characterized and manageable safety and tolerability profile over a long time period [50-56].

\section{- Chemistry}

Teriflunomide is the principal active metabolite of leflunomide (ARAVA ${ }^{\circledR}$, Sanofi, NJ, USA), an immunomodulator approved in 1998 to treat rheumatoid arthritis [57]. Teriflunomide, (Z)-2-cyano-3-hydroxy-but-2-enoic acid(4-trifluoromethylphenyl)-amide, is formulated as film-coated tablets for oral administration [48]. Where available, teriflunomide is marketed only as a $14 \mathrm{mg}$ dose, except in the USA, where the $7 \mathrm{mg}$ dose is also available $[48,49]$.

\section{- Proposed mechanism of action}

An overabundance of activated $\mathrm{T}$ and $\mathrm{B}$ cells in the CNS is thought to mediate the inflammatory damage that occurs in patients with MS [58]. Teriflunomide reversibly inhibits dihydroorotate dehydrogenase, a mitochondrial enzyme necessary for the de novo pyrimidine synthesis required to support the rapid expansion that occurs in antigen-activated lymphocytes [58]. Inhibiting de novo pyrimidine synthesis limits the available pyrimidine pool for T- and B-cell proliferation, thereby decreasing the number of activated $\mathrm{T}$ and $\mathrm{B}$ cells available to cross the blood-brain barrier and enter the CNS [59].

Unlike activated lymphocytes, resting lymphocytes do not require de novo pyrimidine synthesis to self-renew [58]. Consequently, the pyrimidine requirements for homeostatic lymphocyte proliferation can be met by the salvage pathway, which is unaffected by teriflunomide. The presence of this other pathway ensures that teriflunomide selectively inhibits proliferation of activated lymphocytes without interrupting normal homeostatic proliferation of resting lymphocytes (Figure 1) [58].
Further insight into the mechanism of action of teriflunomide came from Teri-DYNAMIC, a nonrandomized, open-label Phase III study to evaluate the effects of teriflunomide on lymphocytes in patients with RRMS [60]. Adaptive immune cell subsets, $\mathrm{CD}^{+}{ }^{+} \mathrm{T}$-cell function and changes in absolute number and clonal diversity of $\mathrm{CD}^{+}{ }^{+} \mathrm{T}$-cell receptors were compared in 39 patients with RRMS who received teriflunomide $14 \mathrm{mg}$ for 24 weeks and 19 untreated healthy participants. In patients with MS, teriflunomide lowered lymphocyte counts, increased $\mathrm{CD}^{+} / \mathrm{CD}^{+}{ }^{+} \mathrm{T}$-cell ratios, and resulted in increased regulatory T-cell counts and reduced Th1 counts. Teriflunomide also significantly reduced clonal diversity of $\mathrm{CD}^{+} \mathrm{T}$ cells. This selective effect on different $\mathrm{CD} 4^{+} \mathrm{T}$-cell subsets suggests a shift in T-cell populations from proinflammatory to regulatory. However, T cells from patients treated with teriflunomide still mounted appropriate proliferative and cytokine responses, consistent with an immunomodulatory rather than immunosuppressive mechanism of action in MS [60].

\section{- Pharmacodynamics, pharmacokinetics \& metabolism}

Key pharmacokinetic characteristics of teriflunomide are shown in Table 1. Systemic exposure to teriflunomide increases in a dose-proportional manner after oral administration over a dose range of 7 to $14 \mathrm{mg}$ [49]. Pharmacokinetic characteristics do not vary significantly with food intake, mild-to-moderate hepatic impairment, renal impairment, gender or age [49].

\section{Clinical efficacy}

Clinical efficacy of teriflunomide has been evaluated extensively in Phase II and Phase III clinical trials in patients with relapsing forms of MS [50-52] and those who have experienced a first clinical episode suggestive of MS [53].

\section{- Phase II study}

The Phase II proof-of-concept study evaluated the efficacy and safety of teriflunomide in patients with relapsing forms of MS (NCT01487096) [50]. In this randomized, double-blind, placebo-controlled trial, 179 patients with MS were randomized (1:1:1) to receive placebo, teriflunomide $7 \mathrm{mg}$ or teriflunomide $14 \mathrm{mg}$ for 36 weeks. Results of the core Phase II study have been previously published [50]. Patients completing the core Phase II study were eligible to participate 


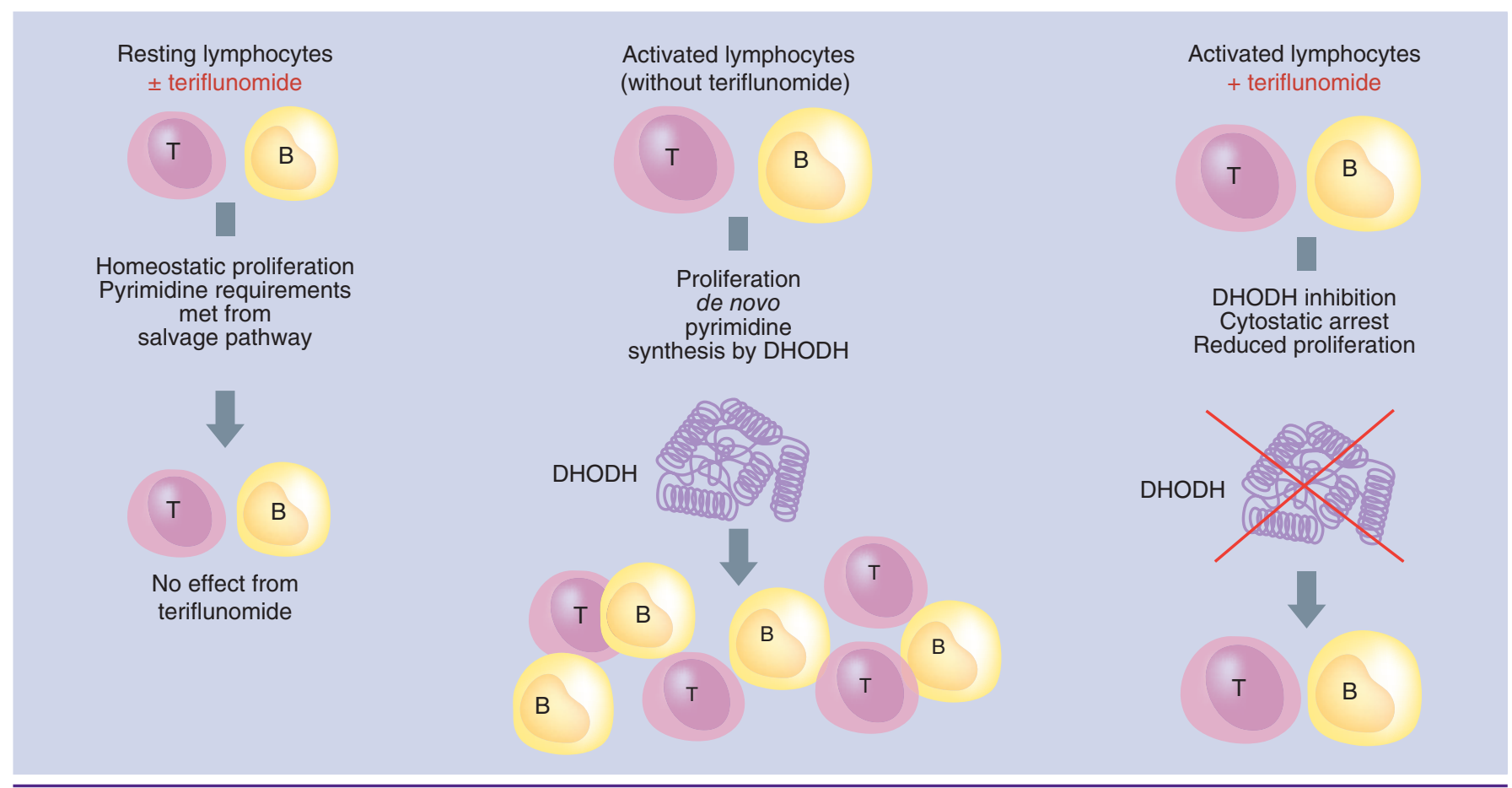

Figure 1. Proposed mechanism of action for teriflunomide [58]. B: B cell; DHODH: Dihydroorotate dehydrogenase; T: T cell.

in an open-label extension in which all patients receiving teriflunomide continued their original dose, and patients who received placebo were rerandomized to either teriflunomide 7 or $14 \mathrm{mg}$. After up to 12 years of teriflunomide exposure, a greater percentage of patients were relapse-free in the teriflunomide $14 \mathrm{mg}$ group $(51.5 \%)$ than in the teriflunomide $7 \mathrm{mg}$ group (39.5\%) [62]. In both groups, relapse rates and Expanded Disability Status Scale (EDSS) scores remained stable and low throughout the follow-up.

\section{- Phase III clinical trials TEMSO}

TEMSO, a randomized, double-blind, placebo-controlled Phase III trial, was the first clinical trial designed to evaluate the effects of teriflunomide on the relapse and disability outcomes of patients with relapsing forms of MS (NCT00134563) [51]. A total of 1088 patients were randomized $(1: 1: 1)$ to receive placebo, teriflunomide $7 \mathrm{mg}$, or teriflunomide $14 \mathrm{mg}$ for 108 weeks, 1086 of whom were treated. Key efficacy outcomes from the TEMSO core study are summarized in Table 2. ARR and 12-week confirmed disability outcomes are shown in Figure 2. Prespecified subgroup analyses of TEMSO showed that the benefits of teriflunomide on ARR and disability confirmed for
12 weeks were consistent across the subgroups of gender, age, geographic region, baseline EDSS strata, relapse history, MS subtype, prior DMT use and MRI parameters (number of Gd-enhancing lesions, total lesion volume) [63].

In a blinded independent analysis of MRIs in TEMSO, the median annualized percentage change in brain volume from baseline to week 48 was calculated using the validated Structural Image Evaluation Using Normalization of Atrophy (SIENA) method [65]. By SIENA, brain volume loss was lower for both teriflunomide groups versus placebo at month 12 (reductions of $34.4 \%$ with teriflunomide $7 \mathrm{mg}, \mathrm{p}=0.0011$, and $36.9 \%$ with teriflunomide $14 \mathrm{mg}, \mathrm{p}=0.0001$ ) and month 24 (reductions of $27.6 \%$ with teriflunomide $7 \mathrm{mg}, \mathrm{p}=0.0019$, and $30.6 \%$ with teriflunomide $14 \mathrm{mg}, \mathrm{p}=0.0001$ ) [65]. These results are not unexpected, given the strong association between brain volume loss and disability worsening, and the positive and consistent effects of teriflunomide on disability worsening observed in TEMSO.

In post hoc analyses of TEMSO, teriflunomide decreased incidence on several measures of severe relapse outcomes [66]. Teriflunomide 14 mg significantly reduced ARRs with sequelae (defined as EDSS/Functional Score increase at 30 days post relapse) by $36 \%(\mathrm{p}=0.0011)$, 
relapse leading to hospitalization by $59 \%$ $(\mathrm{p}<0.0001)$, relapse requiring iv. corticosteroids by $34 \%(\mathrm{p}=0.0003)$ and relapse with sequelae (as determined by the investigator) by $53 \%$ ( $\mathrm{p}<0.0001$ ). Teriflunomide $7 \mathrm{mg}$ significantly reduced ARRs with sequelae (defined by EDSS/Functional Score), relapse leading to hospitalization and relapse requiring iv. corticosteroids [66].

Patients completing TEMSO were eligible to enter the TEMSO extension [55]. Patients who received teriflunomide in the core trial continued this treatment, and those who received placebo were rerandomized $(1: 1)$ to teriflunomide 7 or $14 \mathrm{mg}$. After $\leq 9$ years of teriflunomide treatment, ARRs were further improved compared with the core study: 0.198 and 0.215 for patients continuing teriflunomide 7 and $14 \mathrm{mg}$ and 0.225 and 0.177 for patients switching to teriflunomide 7 or $14 \mathrm{mg}$, respectively. Risk of sustained disability remained low and EDSS scores were stable across all groups [55].

\section{TOWER}

TOWER was a randomized, double-blind, placebo-controlled Phase III trial designed to evaluate the effects of teriflunomide on relapse and disability outcomes in patients with relapsing forms of MS (NCT00751881) [52]. A total of 1169 patients were randomized $(1: 1: 1)$ to receive placebo or teriflunomide 7 or $14 \mathrm{mg}$ for a variable duration, with the study ending 48 weeks after the last patient was randomized. MRI outcomes were not evaluated in this trial [52]. Key efficacy outcomes are summarized in Table 2. ARR and disability worsening confirmed for 12 weeks are shown in Figure 3.

Patients completing TOWER were eligible to enter a long-term extension in which all patients received teriflunomide $14 \mathrm{mg}$ [67]. At the data cut-off (31 July, 2014), patients had received teriflunomide for $\leq 5.5$ years. At the end of the core study, patients who ultimately entered the extension ( $\mathrm{n}=750$ ) had ARRs of 0.305 (core/extension treatment: $7 / 14 \mathrm{mg})$ and $0.257(14 / 14 \mathrm{mg})$. At the end of extension year (EY) 1 and EY2, relapse rates were further decreased in both treatment groups $(0.295$ and $0.188,7 / 14 \mathrm{mg}$ and 0.260 and $0.193,14 / 14 \mathrm{mg}$ EY1 and EY2, respectively). Changes in EDSS from baseline (start of core study) through week 96 of the extension were small and comparable between groups [67]. The risk of disability worsening confirmed for 12 weeks was reduced by $27.6 \%$ in patients who received teriflunomide $14 \mathrm{mg}$ continuously (early treatment) compared with those who switched to teriflunomide $14 \mathrm{mg}$ in the extension (delayed treatment; $\mathrm{p}=0.0473$ ), providing evidence of the importance of early intervention with teriflunomide in relapsing forms of MS [68].

Table 1. Pharmacokinetic characteristics of teriflunomide.

\begin{tabular}{|c|c|c|}
\hline Parameter & Characteristics & Ref. \\
\hline Absorption & $\begin{array}{l}C_{\max }(\text { single oral dose): mean (SD): } \\
-7 \mathrm{mg}: 1.06(0.22) \mu \mathrm{g} / \mathrm{ml} \\
-14 \mathrm{mg}: 2.25(0.47) \mu \mathrm{g} / \mathrm{ml} \\
\text { Rapid absorption. Median time to reach maximum plasma concentrations: } 1-2 \mathrm{~h} \\
\text { post-dose following repeated oral administration } \\
\text { Approximately } 100 \% \text { oral bioavailability }\end{array}$ & [61] \\
\hline Distribution & $\begin{array}{l}\text { Mainly distributed in the plasma } \\
\text { Extensively bound to plasma protein (>99\%) } \\
\text { Volume of distribution: } \sim 11 \text { I after a single iv. administration }\end{array}$ & [61] \\
\hline Metabolism & $\begin{array}{l}\text { Teriflunomide is moderately metabolized and the only component detected in } \\
\text { plasma } \\
\text { Primary biotransformation pathway of teriflunomide is hydrolysis: } \\
\text { - Oxidation is a minor pathway }\end{array}$ & [48] \\
\hline Elimination & $\begin{array}{l}\text { Median half-life: Approximately } 19 \text { days in patients with MS } \\
\text { Eliminated mainly through direct biliary excretion of unchanged drug as well as } \\
\text { renal excretion of metabolites } \\
\text { Two accelerated elimination procedures have been shown to rapidly lower the } \\
\text { plasma concentration of teriflunomide by }>98 \% \text { over } 11 \text { days: } \\
-8 \mathrm{~g} \text { cholestyramine every } 8 \mathrm{~h} \text { for } 11 \text { days. If } 8 \mathrm{~g} \text { is poorly tolerated, } 4 \mathrm{~g} \\
\text { cholestyramine every } 8 \mathrm{~h} \text { may be used } \\
-50 \mathrm{~g} \text { activated charcoal powder every } 12 \mathrm{~h} \text { for } 11 \text { days }\end{array}$ & {$[48,49]$} \\
\hline
\end{tabular}


Table 2. Summary of key end points of Phase III clinical trials of teriflunomide.

\begin{tabular}{|c|c|c|c|c|c|c|c|c|c|c|c|c|}
\hline & \multicolumn{3}{|c|}{$\begin{array}{l}\text { TEMSO (study } \\
\text { duration: } 108 \text { weeks) [51] }\end{array}$} & \multicolumn{3}{|c|}{$\begin{array}{c}\text { TOWER (study } \\
\text { duration: variable; } \\
48 \text { weeks after the last } \\
\text { patient randomized) [52] }\end{array}$} & \multicolumn{3}{|c|}{$\begin{array}{l}\text { TOPIC (study duration: } \\
\quad \leq 108 \text { weeks) } \\
\text { [53] }\end{array}$} & \multicolumn{3}{|c|}{$\begin{array}{c}\text { TENERE (study } \\
\text { duration: variable; } \\
48 \text { weeks after last patient } \\
\text { randomized) }[64]\end{array}$} \\
\hline & \multirow[t]{2}{*}{ Placebo } & \multicolumn{2}{|c|}{ Teriflunomide } & \multirow[t]{2}{*}{ Placebo } & \multicolumn{2}{|c|}{ Teriflunomide } & \multirow[t]{2}{*}{ Placebo } & \multicolumn{2}{|c|}{ Teriflunomide } & \multirow{2}{*}{$\frac{\text { sc. IFNB-1a }}{44 \mu g^{+}}$} & \multicolumn{2}{|c|}{ Teriflunomide } \\
\hline & & $7 \mathrm{mg}$ & $14 \mathrm{mg}$ & & $7 \mathrm{mg}$ & $14 \mathrm{mg}$ & & $7 \mathrm{mg}$ & $14 \mathrm{mg}$ & & $7 \mathrm{mg}$ & $14 \mathrm{mg}$ \\
\hline $\begin{array}{l}\text { Patient number entering } \\
\text { study, } \mathrm{n}\end{array}$ & 363 & 365 & 358 & 388 & 407 & 370 & 197 & 203 & 214 & 104 & 109 & 111 \\
\hline \multicolumn{13}{|l|}{ Clinical end points } \\
\hline ARR & 0.54 & 0.37 & 0.37 & 0.50 & 0.39 & 0.32 & 0.284 & 0.190 & 0.194 & 0.22 & 0.41 & 0.26 \\
\hline $\begin{array}{l}\text { Relative risk reduction (vs } \\
\text { control), } \%\end{array}$ & - & 31.2 & 31.5 & - & 22.3 & 36.3 & - & 33.1 & 31.9 & - & -19 & -4 \\
\hline$p$-value & - & $<0.001$ & $<0.001$ & - & 0.018 & 0.0001 & - & 0.054 & 0.058 & - & 0.03 & 0.59 \\
\hline $\begin{array}{l}\text { Proportion of patients } \\
\text { relapse-free }{ }^{\ddagger} \%\end{array}$ & 45.6 & 53.7 & 56.5 & 60.6 & 71.9 & 76.3 & - & - & - & 84.6 & 57.8 & 76.6 \\
\hline p-value (vs control) & - & 0.01 & 0.003 & - & 0.002 & $<0.001$ & - & - & - & - & - & - \\
\hline $\begin{array}{l}\text { Patients with relapse } \\
\text { indicating } \mathrm{CDMS}^{\S}, \%\end{array}$ & - & - & - & - & - & - & 28 & 19 & 18 & - & - & - \\
\hline $\begin{array}{l}\text { Risk reduction (vs } \\
\text { placebo), } \%\end{array}$ & - & - & - & - & - & - & - & 37.2 & 42.6 & - & - & - \\
\hline $\mathrm{p}$-value & - & - & - & & - & & - & 0.027 & 0.009 & - & - & - \\
\hline $\begin{array}{l}\text { Time to relapse or new } \\
\text { Gd-enhancing or } T_{2} \\
\text { lesions, } \%\end{array}$ & - & - & - & - & - & - & 76 & 62 & 64 & - & - & - \\
\hline $\begin{array}{l}\text { Risk reduction (vs } \\
\text { placebo), } \%\end{array}$ & - & - & - & - & - & - & - & 31.4 & 34.9 & - & - & - \\
\hline$p$-value & - & - & - & - & - & - & - & 0.002 & 0.0003 & - & - & - \\
\hline $\begin{array}{l}\text { Relapse or treatment } \\
\text { discontinuation", \% }\end{array}$ & - & - & - & - & - & - & - & - & - & 42.3 & 48.6 & 37.8 \\
\hline $\mathrm{HR}$ & - & - & - & - & - & - & - & - & - & - & 1.12 & 0.86 \\
\hline p-value (vs control) & - & - & - & - & - & - & - & - & - & - & 0.52 & 0.60 \\
\hline \multicolumn{13}{|l|}{ Disability end points } \\
\hline $\begin{array}{l}\text { Proportion of patients } \\
\text { with sustained disability } \\
\text { worsening confirmed for } \\
12 \text { weeks" } \%\end{array}$ & 27.3 & 21.7 & 20.2 & 19.7 & 21.1 & 15.8 & $10^{+\dagger}$ & $10^{+\dagger}$ & $7^{++}$ & - & - & - \\
\hline $\begin{array}{l}\text { Risk reduction } \\
\text { (vs placebo), \% }\end{array}$ & - & 23.7 & 29.8 & - & 4.5 & 31.5 & - & 2.2 & 29.9 & - & - & - \\
\hline p-value (vs placebo) & - & 0.08 & 0.03 & - & 0.762 & 0.044 & - & 0.995 & 0.424 & - & - & - \\
\hline $\begin{array}{l}\text { Mean change in EDSS } \\
\text { score from baseline }\end{array}$ & - & - & - & 0.09 & 0.04 & -0.05 & -0.056 & -0.250 & -0.265 & - & - & - \\
\hline p-value (vs placebo) & - & - & - & - & 0.482 & 0.043 & - & 0.033 & 0.044 & - & - & - \\
\hline $\begin{array}{l}\text { Mean change in FIS score } \\
\text { from baseline }{ }^{\ddagger \neq}\end{array}$ & 4.3 & 2.3 & 3.8 & 4.67 & 2.51 & 1.92 & -3.535 & -2.730 & -4.487 & 9.10 & 0.97 & 4.10 \\
\hline p-value (vs control) & - & 0.39 & 0.83 & - & 0.309 & 0.208 & - & 0.997 & 0.849 & - & 0.03 & 0.18 \\
\hline
\end{tabular}


Table 2. Summary of key end points of Phase III clinical trials of teriflunomide (cont.).

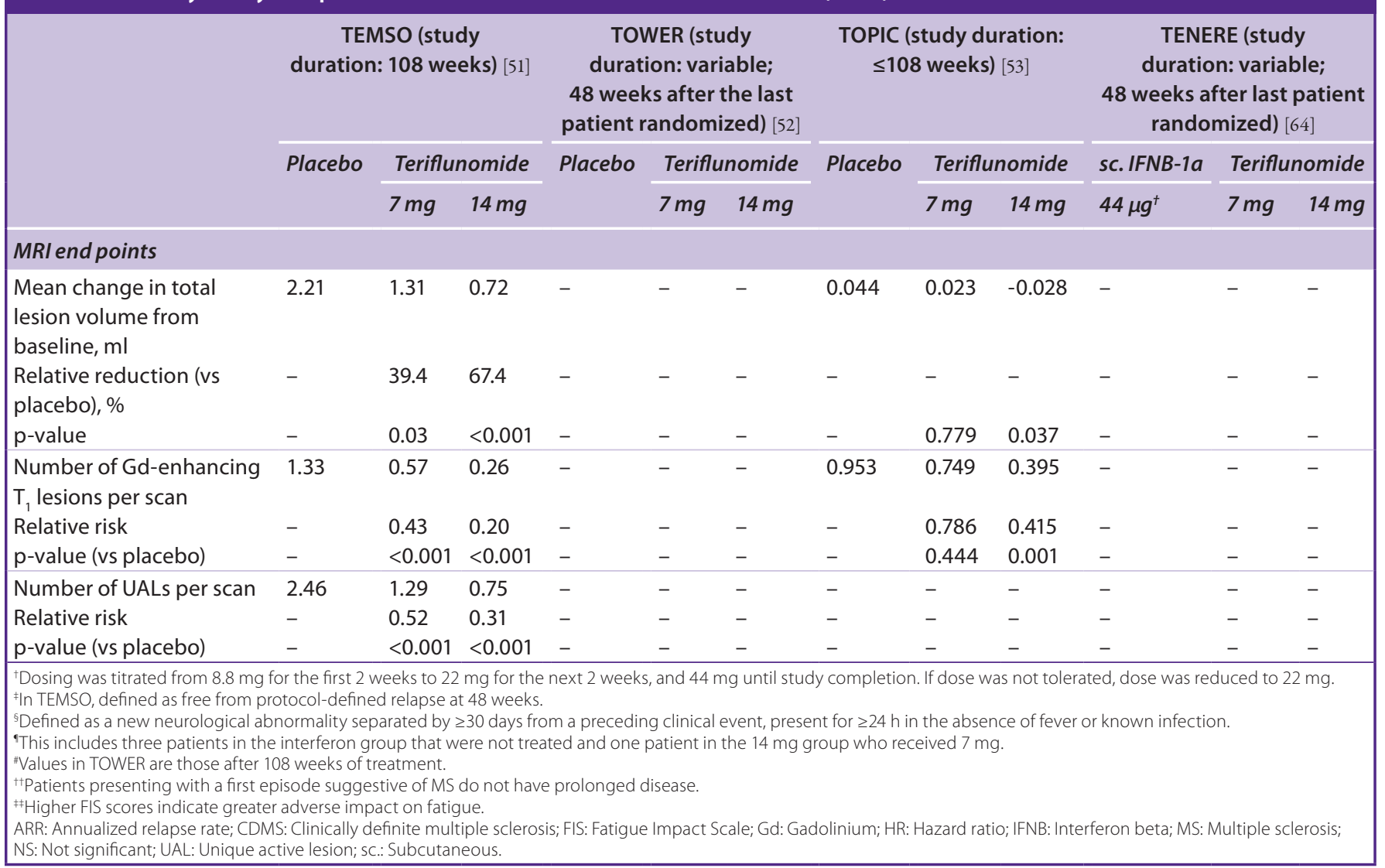

\section{TOPIC}

TOPIC, a randomized, double-blind, placebocontrolled Phase III trial, was designed to evaluate the efficacy of teriflunomide in patients with a first clinical episode suggestive of MS, defined as a new neurological event consistent with demyelination, starting within 90 days of randomization, and with $\geq 2 \mathrm{~T}_{2}$ MRI lesions $\geq 3 \mathrm{~mm}$ in diameter (NCT00622700) [53]. A total of 618 patients were randomized $(1: 1: 1)$ to receive placebo or teriflunomide 7 or $14 \mathrm{mg}$ for 108 weeks. Baseline demographics and disease characteristics were well balanced across treatment groups. Upon entering the trial, the average patient ages were $32.0,31.6$ and 32.8 years in the placebo, teriflunomide 7 and $14 \mathrm{mg}$ groups, respectively; the average time since the initial neurological event was $1.88,1.89$ and 1.80 months, respectively. Patients presenting with a first episode suggestive of MS do not have prolonged disease. Bearing this point in mind facilitates interpretation of the efficacy outcomes summarized for TOPIC in Table 2 [53]. The sponsor of TOPIC filed to stop the trial on 10 August 2012, because revisions to the MS diagnostic criteria in 2010 facilitated earlier diagnoses [69]. Re-evaluation of the power calculation based on available information from the teriflunomide clinical program indicated that the study was still sufficiently powered to detect reduced relapse risk. The TOPIC study demonstrated that teriflunomide was superior to placebo in reducing the risk of relapse indicating clinically definite MS (primary end point), with significant reductions of $37.2 \%$ (hazard ratio [HR]: 0.628 [95\% CI: 0.416-0.949]; $\mathrm{p}=0.027$ ) and $42.6 \%$ (HR: $0.574 \quad$ [0.379-0.869]; $\mathrm{p}=0.009)$ compared with placebo for the 7 and $14 \mathrm{mg}$ doses, respectively [53]. Patients completing the 108-week core study, as well as those who had received $\geq 24$ weeks of treatment and had experienced a relapse that defined clinically definite MS, were eligible to enroll in the TOPIC extension [53]. Patients who had received teriflunomide in the core study continued active treatment, and patients who had received placebo were randomized (1:1) to teriflunomide 7 or $14 \mathrm{mg}$ [53].

\section{TENERE}

TENERE was a randomized, rater-blinded Phase III study that compared the efficacy, 


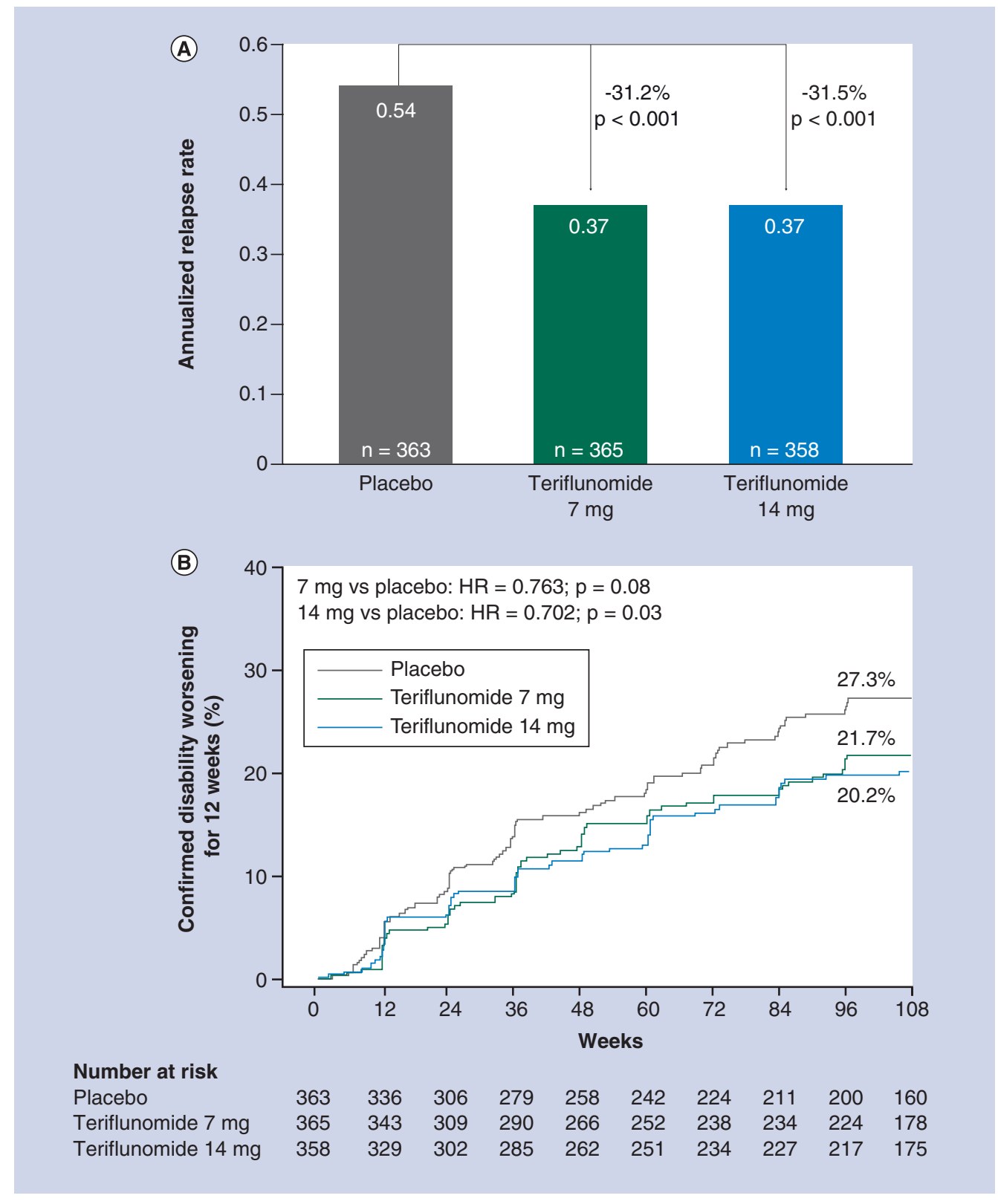

Figure 2. Annualized relapse rate (A) and disability worsening (B) in TEMSO. Modified intent-to-treat population.

HR: Hazard ratio.

Data taken from [51].

safety and tolerability of teriflunomide with subcutaneous (sc.) IFNB-1a in patients with MS (NCT00883337) [64]. A total of 324 patients were randomized $(1: 1: 1)$ to receive $S C$ IFNB-1a $44 \mu \mathrm{g}$ three-times per week or oral teriflunomide 7 or $14 \mathrm{mg}$ once daily. Treatment duration was variable, and like TOWER, ended 48 weeks after the last patient was randomized. Key results are summarized in Table 2. In addition, patients in both teriflunomide groups reported significantly greater satisfaction in the Treatment Satisfaction Questionnaire for Medication (TSQM) domains of Side Effects, Convenience and Global Satisfaction. MRI outcomes were not assessed in TENERE [64].

Participants in the TENERE extension transitioned directly from core study treatment to teriflunomide $14 \mathrm{mg}$ [70]. This direct transition, without a drug-free period, allowed an assessment of the effects of switching from 
sc. IFNB-1a to teriflunomide. Of the 237 patients who entered the TENERE extension, 59 switched from IFNB-1a (sc. IFN/14 mg), 90 switched from teriflunomide $7 \mathrm{mg}(7 / 14 \mathrm{mg})$ and 88 continued to receive teriflunomide $14 \mathrm{mg}(14 / 14 \mathrm{mg})$. In all groups, relapse rates were low $(0.239$, sc. IFN/14 mg; 0.223, $7 / 14 \mathrm{mg}$; and $0.181,14 / 14 \mathrm{mg}$ ); intergroup differences were not significant. Type and rates of AEs were consistent with previous studies, and there were no new or unexpected $\mathrm{AE}$ signals with the switch from sc. IFNB-1a to teriflunomide [70].

\section{- Vaccination studies}

As discussed previously, teriflunomide prevents proliferation of activated lymphocytes by reversibly inhibiting dihydroorotate dehydrogenase [58]. Given this, the effects of teriflunomide on the immune response to vaccines were investigated
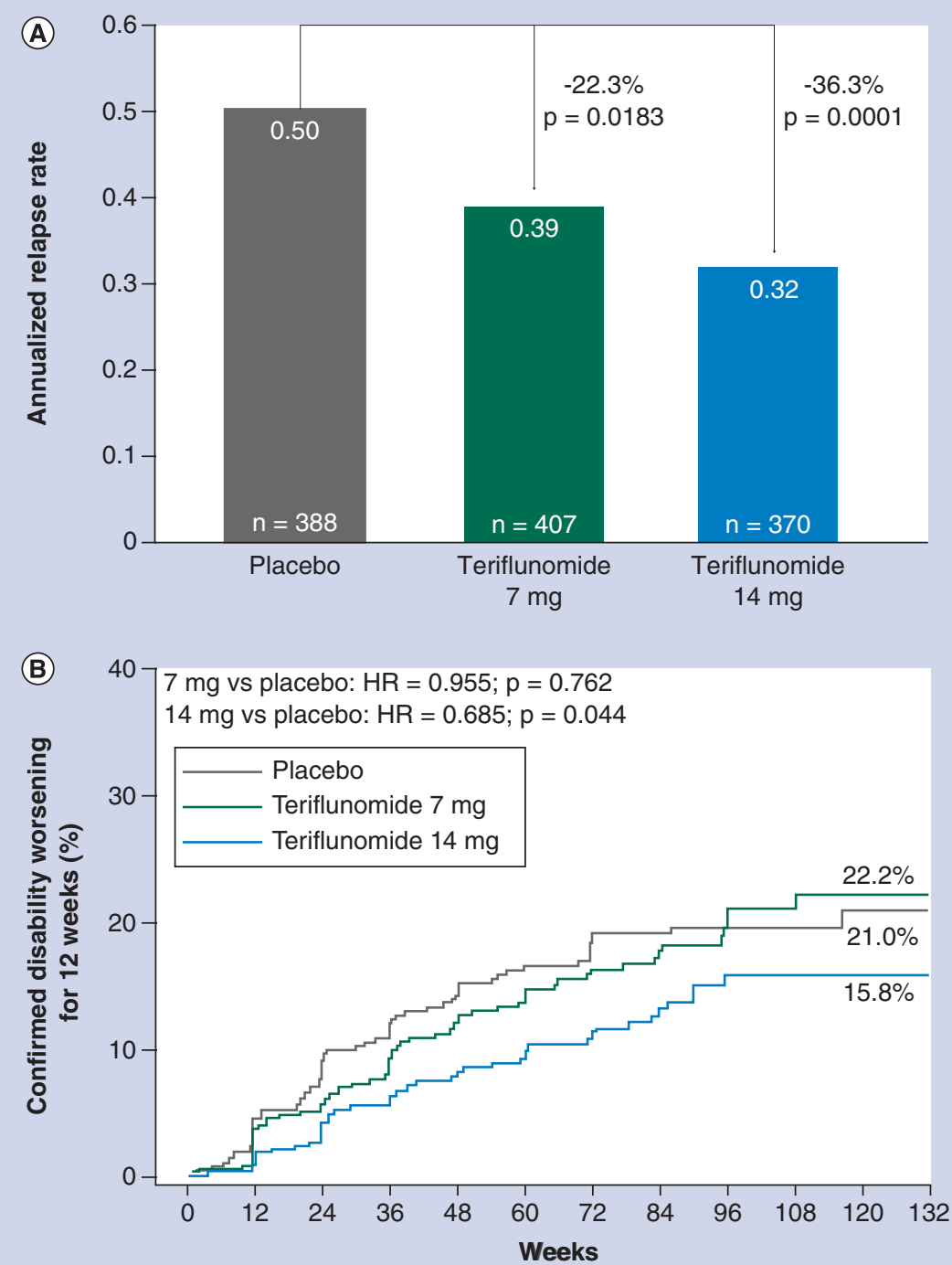

Number at risk

Figure 3. Annualized relapse rate (A) and disability worsening (B) in TOWER. Modified intent-to-treat population.

HR: Hazard ratio.

Data taken from [52]. 
in two studies [71,72]. In TERIVA, the immune responses to a recall antigen (influenza vaccine) were measured in patients with relapsing forms of MS, on a stable dose of IFNB, teriflunomide 7 or $14 \mathrm{mg}$ [71]. Overall, teriflunomide did not adversely affect the ability of patients to successfully mount an immune response to the vaccine. In the second vaccination study, healthy subjects receiving teriflunomide were able to mount an effective response to a neoantigen challenge (rabies vaccine) [72]. Together, these studies demonstrate that immune responses are preserved during teriflunomide treatment, providing further supportive evidence for a selective immunomodulatory mechanism of action for teriflunomide.

\section{- Supplementary measures of efficacy Number needed to treat}

Obtaining measures of comparative efficacy between different treatment options is important to help inform clinical decisions in the absence of head-to-head comparative studies [6]. NNT is a parameter designed to facilitate cross-trial comparisons by expressing treatment efficacies as the number of patients that need to be treated with a given therapy to prevent one occurrence of a given event [73]. NNT, which is derived from absolute risk reduction, has become a useful tool for comparing clinical outcomes in a range of disease areas, including MS [73,74]. A lower NNT reflects a greater benefit of therapeutic intervention [6].

The NNT approach has been used to compare relapse rates of patients with MS who received teriflunomide with those treated with DMF [75]. In DEFINE [31] and CONFIRM [30], twice-daily DMF showed a greater relative risk reduction (53 and $44 \%$ vs placebo, respectively) than teriflunomide $14 \mathrm{mg}$ in TEMSO [51] and TOWER [52] (31.5 and $36.3 \%$, respectively). However, the NNT to prevent one relapse was comparable between DMF (5.3 in DEFINE and 5.6 in CONFIRM) and teriflunomide $14 \mathrm{mg}$ (5.9 in TEMSO and 5.6 in TOWER) [75]. Furthermore, NNT to prevent a relapse leading to hospitalization was significantly reduced versus placebo in both TEMSO and TOWER, but not in DEFINE or CONFIRM; corresponding NNTs were 12.5 (TEMSO) and 20 (TOWER), and 50 in both DEFINE and CONFIRM. NNTs to prevent disability worsening were $13.8,17.4$, 10.8 and 30.2 for TEMSO, TOWER, DEFINE and CONFIRM, respectively [75].
No evidence of disease activity

NEDA is a composite measure of efficacy that includes clinical (no confirmed clinical relapse; no disability worsening confirmed for 12 weeks) and MRI outcomes (no Gd-enhancing $\mathrm{T}_{1}$ lesions and no new/enlarging $\mathrm{T}_{2}$ lesions) [76].

NEDA has been assessed in post hoc analyses of TEMSO core and extension studies [76-78]. From baseline to the end of the 2-year core study, NEDA was achieved by significantly more patients in the teriflunomide $14 \mathrm{mg}$ group than in the placebo group ( 22.9 vs $14.3 \%$; odds ratio [OR] 1.78; $\mathrm{p}=0.0031$ ); more patients reached NEDA in the $7 \mathrm{mg}$ group than placebo, but this was not significant (18.4 vs $14.3 \%$, respectively) [76]. To ensure that residual disease activity was not an influencing factor in NEDA assessments and that the full therapeutic effect of teriflunomide had been attained, achievement of NEDA from month 6 to year 2 was also evaluated [77]. During this period, NEDA achievement was greater with teriflunomide $14 \mathrm{mg}$ (28.1\%; OR: 2.34; $\mathrm{p}<0.0001)$ or $7 \mathrm{mg}$ (21.5\%; OR: $1.64 ; \mathrm{p}=0.0180)$ than placebo (14.3\%) [77].

mRio score

The mRio system was developed to predict future disability worsening based on MRI and relapse criteria. The number of relapses and occurrence of new $\mathrm{T}_{2}$ lesions (6-monthly MRI scans) were evaluated during the first year of treatment. After 1 year of treatment, patients were classified using the mRio score for risk of disease worsening/treatment response according to relapse status ( 0 to $\geq 2$ relapses) and the occurrence of active $T_{2}$ lesions ( $\leq$ or $>5$ lesions over 1 year). Patients with scores of 0,1 or $2-3$, were categorized as having a low, intermediate or high risk of treatment response, respectively [79]. In a post hoc analysis of TEMSO, patients treated with teriflunomide (7 and $14 \mathrm{mg}$ groups combined) with a computable $\mathrm{mRio}$ score at the end of year 1 were classified based on their $\mathrm{mRio}$ scores as $0,63.4 \%(\mathrm{n}=350) ; 1,25.9 \%(\mathrm{n}=143)$; and 2 or 3, $10.7 \%(n=59)$, compared with $48.8 \%$ $(\mathrm{n}=139), 32.6 \%(\mathrm{n}=93)$, and $18.6 \%(\mathrm{n}=53)$ of patients who received placebo, respectively. Over 384 weeks ( $>7$ years) from study initiation, the risk of disability worsening confirmed for 12 weeks in teriflunomide patients in the score 0 (treatment responder) category was significantly reduced compared with patients in the score 2 or 3 (nonresponder) category (HR: 2.055; 
$\mathrm{p}<0.05)$. These data demonstrate that relapses and MRI lesions in the first 1.5 years of treatment can be predictive of subsequent disability worsening [79].

\section{- Real-world experience}

\section{Teri-PRO}

Teri-PRO is a prospective, nonrandomized, open-label, global Phase IV study in which patients with relapsing forms of MS received teriflunomide per local labeling [80]. Enrollment is complete, with 1001 patients enrolled across sites in the USA, Canada, Europe and Latin America. The primary end point was global patient satisfaction with teriflunomide treatment, measured by TSQM (version 1.4). Patient-reported disability, measured with the MS Performance Scale, was a secondary end point. In the USA, a total of 545 patients were included, of which 13.2 and $86.8 \%$ received teriflunomide 7 or $14 \mathrm{mg}$, respectively. In interim results, at week 4 these patients had a mean TSQM Global Satisfaction score of 72.2 (0-100; higher scores indicate greater satisfaction). For patients who had switched to teriflunomide from a different DMT, the mean TSQM Global score was 74.9, a 22.7-point improvement from teriflunomide initiation (baseline). At week 24 ( $\mathrm{n}=442)$, mean MS Performance Scale score was 14.1 , a decrease of 0.7 points from baseline, indicating stable levels of patient-reported disability. At week 24 or end of treatment, 73.4\% of US patients reported AEs, and a total of $9.2 \%$ of patients discontinued treatment because of an AE. The safety and tolerability profile of teriflunomide for US patients in the Teri-PRO study at week 24, as well as the low rate of treatment discontinuation, was consistent with that seen in Phase II and III studies [80].

An interim analysis of study results from patients enrolled in Canada, Europe and Latin America demonstrated similar results. At week 4 , the mean TSQM Global Satisfaction score for all patients $(\mathrm{n}=233)$ was 73.9. The mean TSQM improvement from baseline to week 4 was 22.4 in patients switching from another DMT $(\mathrm{n}=115)$ [81].

\section{- Switching to teriflunomide from other DMTs}

Patients who require a switch to an alternative DMT may be suboptimal responders and have a potential risk for more rapid disease worsening. In addition to observations in 'switcher' populations of Teri-PRO, further insight has been gleaned from analyses of the TEMSO and TOWER studies, which required transitional interval of 3 and 4 months, respectively, between a prior treatment and teriflunomide, and the TENERE extension, which allowed a direct transition from IFNB-1a to teriflunomide [82]. In a post hoc analysis of pooled data from TEMSO and TOWER, teriflunomide $14 \mathrm{mg}$ consistently reduced ARR in all prior DMT subgroups compared with placebo, with no significant treatment-by-subgroup interactions. Teriflunomide safety was also consistent across these subgroups [82]. The TENERE extension (discussed above) also yielded information about the efficacy and safety of switching from IFNB to teriflunomide $14 \mathrm{mg}$ [70]; relapse rates were low in all treatment groups $(0.239, \mathrm{SC}$ IFN/14 mg; $0.223,7 / 14 \mathrm{mg}$; and $0.181,14 / 14 \mathrm{mg}$ ), and intergroup differences were not significant. No new or unexpected safety events were associated with switching from IFNB-1a to teriflunomide [70].

The effect of switching from NTZ to teriflunomide $14 \mathrm{mg}$ within 4 weeks of the final NTZ dose is currently being investigated in a prospective study [82]. In a 6-month interim analysis, EDSS scores for 13 of 15 patients remained stable or showed an improvement. The two remaining patients experienced new $\mathrm{Gd}$-enhancing lesions. There was no incidence of PML [82].

\section{Safety \& tolerability}

\section{- Pooled teriflunomide studies}

Teriflunomide has a well-characterized, manageable safety and tolerability profile that is consistent across studies; safety data from individual studies have been previously reported [50-54]. To gain further insight into the safety and tolerability profile of teriflunomide, results from the teriflunomide clinical trial database have been pooled and analyzed [83]. Safety data were divided into two pools to compare the safety outcomes associated with long-term teriflunomide treatment (Pool 2) with safety outcomes observed in placebo-controlled core studies (Pool 1) [83]. Pool 1 consisted of data from placebo-controlled, double-blind core studies: Phase II, TEMSO, TOWER and TOPIC [83]. A total of 3044 patients were included in Pool 1, with a cumulative treatment duration of $>1500$ patient-years in each treatment group (placebo, teriflunomide $7 \mathrm{mg}$, and $14 \mathrm{mg}$ ). Pool 2 included data from Pool 1 core studies and long-term extension data from the Phase II and TEMSO studies. All patients in Pool 2 had been exposed to teriflunomide. Pool 2 was used to include long-term safety available at the time to determine whether 
there was any change in the safety profile with long-term exposure to teriflunomide. The 2338 patients in Pool 2 had a maximum exposure of 12.1 years and a cumulative treatment duration of $>3304$ patient-years per treatment group [83]. Pooled safety data are shown in Tables $3 \& 4$. The nature of AEs reported in Pool 2 was similar to that of AEs observed in Pool 1, and no new or unexpected events were associated with longterm teriflunomide exposure across a wide spectrum of disease, from patients presenting with a first event to those with secondary progressive disease with relapses [83].

\section{- Treatment discontinuations due to AEs}

The majority of events in both pools was of mild-to-moderate intensity, was self-limiting and infrequently resulted in discontinuation of therapy. The most common reason for treatment discontinuation in all treatment groups was alanine aminotransferase (ALT) elevation, reflecting the protocol requirement to discontinue treatment on confirmation of ALT $>3 \times$ the upper limit of normal. Teriflunomide safety and tolerability in the pooled data were consistent with results from individual studies, with no new or unexpected safety signals identified in these pooled analyses [83].

\section{- AEs of special interest}

The incidence of AEs of special interest for Pool 1 is shown in Table 3.

Patients treated with teriflunomide had a higher incidence of hepatic events, mainly owing to reversible ALT increases $\leq 3 \times$ the upper limit of normal [76]. Longer term exposure (Pool 2) did not appear to increase clinically relevant hepatic events. Onset of hepatic events usually occurred during the first 6 months, events were mainly mild to moderate in nature and the majority of patients recovered [83].

In Pool 1, lymphopenia and neutropenia occurred more frequently in patients treated with teriflunomide and were generally observed during the first 6 weeks or 3 months of treatment, respectively, followed by stabilization with continued treatment. Actual mean decreases for both neutrophils and lymphocytes were generally no more than $15 \%$, with mean counts remaining in the normal range [83]. One case of serious thrombocytopenia, potentially related to an immune-mediated mechanism, was considered to have had a possible causal relationship with teriflunomide. Similar results were observed in Pool 2, in which the proportion of patients with neutropenia was 4.3 and $6.3 \%$, and lymphopenia was 0.5 and $0.8 \%$, for teriflunomide 7 and $14 \mathrm{mg}$, respectively [83].

Infections and serious infections occurred at similar rates in all Pool 1 treatment groups and there was no relationship between neutrophil count decrease and the occurrence of infections. Serious opportunistic infections occurred in two placebo patients (acute herpes zoster and hepatitis C with cytomegalovirus infection), one teriflunomide $7 \mathrm{mg}$ patient (pulmonary tuberculosis) and two teriflunomide $14 \mathrm{mg}$ patients (gastrointestinal tuberculosis and hepatitis with cytomegalovirus infection) [83]. Both patients with tuberculosis recovered following treatment with antituberculosis agents. Opportunistic infections led to treatment discontinuation in three patients in the $7 \mathrm{mg}$ group and two patients in the $14 \mathrm{mg}$ group. In Pool 2, one additional serious opportunistic oral herpes infection was reported in the teriflunomide $7 \mathrm{mg}$ group; the patient recovered [83].

Malignancies did not occur at a higher rate in patients receiving teriflunomide in Pool 1 [83]. Thyroid cancer $(\mathrm{n}=1)$, cervical carcinoma stage $0(n=1)$ and breast cancer $(n=2)$ were reported in the placebo group, and one patient in the teriflunomide $14 \mathrm{mg}$ group was diagnosed with cervical carcinoma stage 0 . In Pool 2, all malignancies were solid tumors, with no unusual pattern, and no cases of lymphoproliferative or hematological malignancies were observed [83].

In Pool 1, hypertension occurred more frequently with teriflunomide and the risk was greater in patients with pre-existing hypertension [83]. In Pool 2, hypertension was reported in 8.5 and $9.2 \%$ of patients treated with teriflunomide 7 and $14 \mathrm{mg}$, respectively. Most patients were successfully managed with the introduction of, or modification of existing, antihypertensive treatment [83].

In Pool 1, a small number of cases of peripheral neuropathy confirmed by nerve conduction studies occurred, leading to discontinuation of three patients in the teriflunomide $7 \mathrm{mg}$ group and five patients in the $14 \mathrm{mg}$ group [83].

No pulmonary disorders that could be attributed to interstitial lung disease were observed in Pool 1 [83]. One potential case, unlikely to be related to teriflunomide, was identified on day 1 of the extension study in a patient in the $14 \mathrm{mg}$ group of Pool 2 who had a severe cold and history of tobacco use [83].

Pancreatic disorders occurred at similar rates in the three groups in Pool 1. Most disorders were asymptomatic, and enzyme increases were 
Table 3. Overview of safety outcomes in Pool 1 (placebo-controlled, double-blind core studies): Phase II, TEMSO, TOWER and TOPIC.

\begin{tabular}{|c|c|c|c|}
\hline Patients with adverse events & $\begin{array}{l}\text { Placebo } \\
(n=997), n(\%)\end{array}$ & $\begin{array}{l}\text { Teriflunomide } 7 \mathrm{mg} \\
(\mathrm{n}=1045), \mathrm{n}(\%)\end{array}$ & $\begin{array}{l}\text { Teriflunomide } 14 \mathrm{mg} \\
(\mathrm{n}=1002), \mathrm{n}(\%)\end{array}$ \\
\hline All adverse events & $853(85.6)$ & $895(85.6)$ & $885(88.3)$ \\
\hline Serious adverse event & $119(11.9)$ & $125(12.0)$ & $133(13.3)$ \\
\hline $\begin{array}{l}\text { Event leading to permanent treatment } \\
\text { discontinuation }\end{array}$ & $75(7.5)$ & $117(11.2)$ & $125(12.5)$ \\
\hline Deaths & $2(0.2)$ & $1(<0.1)$ & $2(0.2)$ \\
\hline \multicolumn{4}{|l|}{ Intensity ${ }^{+}$: } \\
\hline - Mild & $285(33.4)$ & $294(32.8)$ & $281(31.8)$ \\
\hline - Moderate & $448(52.5)$ & $480(53.6)$ & $477(53.9)$ \\
\hline - Severe & $120(14.4)$ & $121(13.5)$ & $127(14.4)$ \\
\hline \multicolumn{4}{|l|}{ Common adverse events ${ }^{\ddagger}$} \\
\hline Headache & $150(15.0)$ & $186(17.8)$ & $157(15.7)$ \\
\hline ALT increase & $98(9.8)$ & $136(13.0)$ & $150(15.0)$ \\
\hline Diarrhea & $75(7.5)$ & $137(13.1)$ & $136(13.6)$ \\
\hline Hair thinning ${ }^{\S}$ & $50(5.0)$ & $102(9.8)$ & $135(13.5)$ \\
\hline Nausea & $72(7.2)$ & $84(8.0)$ & $107(10.7)$ \\
\hline \multicolumn{4}{|c|}{ Common adverse events leading to treatment discontinuation" } \\
\hline ALT increase & $23(2.3)$ & $34(3.3)$ & $26(2.6)$ \\
\hline Hair thinning ${ }^{\S}$ & $1(0.1)$ & $2(0.2)$ & $13(1.3)$ \\
\hline Pregnancy & $3(0.3)$ & $6(0.6)$ & $8(0.8)$ \\
\hline Neutropenia & 0 & $6(0.6)$ & $8(0.8)$ \\
\hline Transaminases increase & $6(0.6)$ & $5(0.5)$ & $5(0.5)$ \\
\hline Hepatic enzyme increase & $5(0.5)$ & $2(0.2)$ & $5(0.5)$ \\
\hline Diarrhea & $1(0.1)$ & $5(0.5)$ & $4(0.4)$ \\
\hline AST increase & $2(0.2)$ & $6(0.6)$ & $3(0.3)$ \\
\hline Abdominal pain upper & 0 & $5(0.5)$ & $1(<0.1)$ \\
\hline \multicolumn{4}{|l|}{ Adverse events of special interest } \\
\hline Hepatic disorders & $152(15.2)$ & $207(19.8)$ & $215(21.5)$ \\
\hline $\begin{array}{l}\text { Hematological measures: } \\
\text { - Neutropenia } \\
\text { - Lymphopenia }\end{array}$ & $\begin{array}{l}19(1.9) \\
2(0.2)\end{array}$ & $\begin{array}{l}44(4.2) \\
4(0.4)\end{array}$ & $\begin{array}{l}59(5.9) \\
5(0.5)\end{array}$ \\
\hline Infections: & $532(53.4)$ & $553(52.9)$ & $528(52.7)$ \\
\hline - Serious infections & $22(2.2)$ & $23(2.2)$ & $27(2.7)$ \\
\hline Malignancies & $4(0.4)$ & 0 & $1(<0.1)$ \\
\hline Hypertension & $27(2.7)$ & $47(4.5)$ & $53(5.3)$ \\
\hline Peripheral neuropathy confirmed by NCS & $4(0.4)$ & $13(1.4)$ & $17(1.9)$ \\
\hline Pancreatic disorders & $28(2.8)$ & $27(2.6)$ & $27(2.7)$ \\
\hline Hair thinning ${ }^{\#}$ & $51(5.1)$ & $105(10.0)$ & $139(13.9)$ \\
\hline $\begin{array}{l}\text { Gastrointestinal events: } \\
\text { - Nausea } \\
\text { - Diarrhea }\end{array}$ & $\begin{array}{l}72(7.2) \\
76(7.6)\end{array}$ & $\begin{array}{l}84(8.0) \\
138(13.2)\end{array}$ & $\begin{array}{l}107(10.7) \\
136(13.6)\end{array}$ \\
\hline \multicolumn{4}{|c|}{$\begin{array}{l}\text { †Mild: no modification of daily activities and/or does not require symptomatic treatment; Moderate: hinders normal daily activities } \\
\text { and/or requires symptomatic treatment; Severe: prevents daily activities and requires symptomatic treatment. Calculated as } \\
\text { percentage of patients with adverse events. } \\
\text { "Events with a crude incidence rate of } \geq 10 \% \text { in either teriflunomide group, and } \geq 2 \% \text { greater than placebo, listed in descending order } \\
\text { for the teriflunomide } 14 \mathrm{mg} \text { group. } \\
\text { sMedDRA-preferred term: alopecia. } \\
\text { 'Events occurring in } \geq 5 \text { patients in either teriflunomide group, listed in descending order for the teriflunomide } 14 \mathrm{mg} \text { group. } \\
\text { "Including related terms such as decreased hair density or hair loss. } \\
\text { ALT: Alanine aminotransferase; AST: Aspartate aminotransferase; MedDRA: Medical Dictionary for Regulatory Activities; NCS: Nerve } \\
\text { conduction studies. } \\
\text { Data taken from [83]. }\end{array}$} \\
\hline
\end{tabular}


Table 4. Overview of safety outcomes in Pool 2 (all patients treated with teriflunomide): Pool 1 plus Phase II and TEMSO long-term extensions.

\begin{tabular}{|c|c|c|}
\hline Patients with adverse events ${ }^{\dagger}$ & $\begin{array}{l}\text { Teriflunomide } 7 \mathrm{mg}(\mathrm{n}=1204) \text {, } \\
\mathrm{n}(\%)\end{array}$ & $\begin{array}{l}\text { Teriflunomide } 14 \mathrm{mg}(\mathrm{n}=1134) \text {, } \\
\mathrm{n}(\%)\end{array}$ \\
\hline All adverse events & $1056(87.7)$ & $1020(89.9)$ \\
\hline Serious adverse event & $246(20.4)$ & $219(19.3)$ \\
\hline $\begin{array}{l}\text { Event leading to permanent } \\
\text { treatment discontinuation }\end{array}$ & $184(15.3)$ & $172(15.2)$ \\
\hline Death & $4(0.3)$ & $4(0.4)$ \\
\hline \multicolumn{3}{|l|}{ Intensity ${ }^{\ddagger}$ : } \\
\hline - Mild & $270(22.4)$ & $252(22.2)$ \\
\hline - Moderate & $559(46.4)$ & $558(49.2)$ \\
\hline - Severe & $227(18.9)$ & $210(18.5)$ \\
\hline \multicolumn{3}{|l|}{ Common adverse events ${ }^{\S}$} \\
\hline Nasopharyngitis & $278(23.1)$ & $272(24.0)$ \\
\hline Headache & $256(21.3)$ & $215(19.0)$ \\
\hline ALT increased & $205(17.0)$ & $211(18.6)$ \\
\hline Diarrhea & $189(15.7)$ & 192 (16.9) \\
\hline Fatigue & $177(14.7)$ & $170(15.0)$ \\
\hline Hair thinning? & $127(10.5)$ & $166(14.6)$ \\
\hline Back pain & $150(12.5)$ & $157(13.8)$ \\
\hline Influenza & $136(11.3)$ & $149(13.1)$ \\
\hline Upper respiratory tract infection & $153(12.7)$ & $145(12.8)$ \\
\hline Nausea & $120(10.0)$ & $142(12.5)$ \\
\hline Urinary tract infection & $136(11.3)$ & $130(11.5)$ \\
\hline Paresthesia & $115(9.6)$ & $129(11.4)$ \\
\hline Pain in extremity & $128(10.6)$ & $123(10.8)$ \\
\hline Arthralgia & $138(11.5)$ & $103(9.1)$ \\
\hline \multicolumn{3}{|c|}{$\begin{array}{l}\text { 'Includes patients initially randomized to placebo in core studies. } \\
\text { "Mild: no modification of daily activities and/or does not require symptomatic treatment; Moderate: hinders normal daily activities } \\
\text { and/or requires symptomatic treatment; Severe: prevents daily activities and requires symptomatic treatment. } \\
\text { 'Events with a crude incidence rate of } \geq 10 \% \text { in either teriflunomide group; listed in descending order in the teriflunomide } 14 \text { mg } \\
\text { group. } \\
\text { 'MedDRA-preferred term: alopecia. } \\
\text { ALT: Alanine aminotransferase; MedDRA: Medical Dictionary for Regulatory Activities. } \\
\text { Data taken from [83]. }\end{array}$} \\
\hline
\end{tabular}

reversible. Serious pancreatitis was reported in two patients receiving placebo and one patient receiving teriflunomide $7 \mathrm{mg}$ [83].

In Pool 1, teriflunomide groups had a higher incidence of gastrointestinal events. Most cases were mild to moderate in intensity and rarely led to discontinuation; most patients recovered during the observation period [83]. In Pool 2, nausea was reported by 10.0 and $12.5 \%$ of patients in the 7 and $14 \mathrm{mg}$ groups; 15.7 and $16.9 \%$ reported diarrhea, respectively [83].

In Pool 1, hair thinning occurred more frequently in patients receiving teriflunomide; no events were classified as serious [83]. Hair thinning led to treatment discontinuation in 0.1 , 0.2 and $1.3 \%$ of patients in the placebo and teriflunomide 7 and $14 \mathrm{mg}$ groups, respectively. Hair thinning typically occurred during the first 6 months of teriflunomide treatment; no complete hair loss was reported and most cases resolved without treatment discontinuation. In Pool 2, hair thinning was similar, occurring in 11 and $15.3 \%$ of patients in the teriflunomide 7 and 14 mg groups, respectively [83]. An evaluation of hair thinning in real-world clinical practice is discussed in further detail below [84].

\section{- Hair thinning}

Hair thinning may be a particular concern for a number of patients. Hair thinning associated with teriflunomide is characteristic of telogen effluvium, a common cause of reversible hair loss due to premature transition of follicles to the resting phase. This mechanism is distinct from the rapid and complete hair loss of anagen effluvium, typically observed following chemotherapy, when hair growth in the active anagen phase is interrupted [85]. Across all clinical trials, hair thinning 
was reported in 10.0 and $13.9 \%$ of patients in teriflunomide 7 and $14 \mathrm{mg}$ groups, respectively, versus $5.1 \%$ with placebo [83]. At nine MS treatment centers in the USA, patients with RRMS who reported hair thinning to healthcare professionals during teriflunomide treatment were eligible to enroll in the hair thinning photo project [84]. In this project, hair thinning was evaluated using patient and physician questionnaires administered at the onset and follow-up, and a standardized series of photographs of hair thinning was taken [84]. In all, 38 patients completed their participation, most of whom were female, white and with no prior history of hair loss [86]. For these 38 patients the mean duration between teriflunomide initiation and onset of hair thinning was 77 days, and physicians classified all but one case as mild (63\%) or moderate $(34 \%)$. The mean patient-perceived severity score was 5.1/10. At follow-up, 79\% of patients reported either complete or near-complete resolution or marked improvement of hair thinning; only one patient described minimal improvement (hair thinning was rated as mild by the healthcare provider and $2 / 10$ by the patient at both visits) [86].

\section{- Pregnancy}

Based on animal data, teriflunomide may cause major birth defects if used during pregnancy. Pregnancy must be excluded before starting teriflunomide. Teriflunomide is contraindicated in pregnant women or women of childbearing potential who are not using reliable contraception. Pregnancy must be avoided during teriflunomide treatment or prior to the completion of an accelerated elimination procedure after teriflunomide treatment [48]. However, to date, no pregnancy safety concerns have been identified in the teriflunomide clinical development program. Furthermore, prospective studies of leflunomide conducted by the Organization of Teratology Information Specialists and 2.4 million patient-years of leflunomide postmarketing surveillance have also not shown any teratogenic signal in humans [87]. Nevertheless, pregnancy must be excluded before teriflunomide treatment, and patients must use reliable contraception during and after treatment. An accelerated elimination procedure (to reduce plasma concentrations of teriflunomide to $<0.02 \mu \mathrm{g} / \mathrm{ml}$ ) is recommended for women who have taken teriflunomide and wish to become pregnant and for those who become pregnant during treatment despite the contraindication [48]. In Denmark, pregnancy guidelines for women taking teriflunomide have been recently modified to be somewhat less conservative, recommending teriflunomide as a first-line first-choice therapy for women with MS who do not wish to become pregnant within the coming year [88].

A total of 83 pregnancies were reported in the teriflunomide clinical trial program, despite requirements for reliable use of contraception [89]. The outcomes of these pregnancies are shown in Table 5. No structural or functional abnormalities were noted at birth for babies born to patients exposed to teriflunomide and the spontaneous abortion rate in teriflunomide-exposed women was $18.6 \%$, within the range for the general population. None of the induced abortions were due to defects or malformations [89,90].

Because teriflunomide-pregnancy exposure data are limited, two pregnancy registries have been established to collect additional prospective data. In the USA, the Organization of Teratology Information Specialists is maintaining a teriflunomide pregnancy registry [91] and an International Teriflunomide Pregnancy Exposure Registry has been established to monitor pregnancy outcomes in 17 additional countries [92]. This latter registry aims to recruit a total of 196 pregnant women exposed to teriflunomide to achieve 104 live births. Enrollment began in 2015 and will continue through December 2019. Pregnancy outcomes of study participants will be compared with those reported by the population-based European Surveillance of Congenital Anomalies.

\section{Regulatory affairs}

As of February 2016, teriflunomide has been approved in 63 countries. In the USA, both the 7 and $14 \mathrm{mg}$ doses of teriflunomide have been approved for the treatment of relapsing forms of MS. In other countries, only the $14 \mathrm{mg}$ dose has been approved. In the European Union, the approved indication is for treatment of adult patients with RRMS.

\section{Conclusion}

Teriflunomide treatment has had consistent effects on multiple markers of disease activity in patients with relapsing forms of MS or those with a first clinical episode suggestive of MS. In multiple clinical trials, patients with MS have shown improvements in disease measures, including ARR, disability worsening and MRI outcomes. These 
Table 5. Outcomes of pregnancies in female patients and partners of male patients in the teriflunomide clinical trial program.

\begin{tabular}{|c|c|c|c|}
\hline Pregnancy outcome & Placebo (n) & Teriflunomide (n) & IFNB (n) \\
\hline \multicolumn{4}{|l|}{ Female patients } \\
\hline Live birth & 2 & 26 & 2 \\
\hline Induced abortion & 8 & 29 & 0 \\
\hline Spontaneous abortion & 1 & 13 & 0 \\
\hline Ongoing pregnancy & 0 & $1^{\dagger}$ & 0 \\
\hline Unknown & 0 & 1 & 0 \\
\hline Total & 11 & 70 & 2 \\
\hline \multicolumn{4}{|c|}{ Female partners of male patients } \\
\hline Live birth & 2 & 16 & - \\
\hline Induced abortion & 1 & 2 & - \\
\hline Spontaneous abortion & 0 & 1 & - \\
\hline Total & 3 & 19 & - \\
\hline
\end{tabular}

improvements in ARR and disability worsening have been maintained in long-term extensions of the pivotal Phase III trials TEMSO and TOWER. Teriflunomide is the only currently approved oral DMT with positive disability results in two Phase III trials. In TEMSO, the positive and significant MRI outcomes observed with teriflunomide have been supported by a standardized analysis of brain atrophy using the SIENA method, which showed significantly reduced brain volume loss after 12 and 24 months of teriflunomide versus placebo. These positive efficacy outcomes are supported by results from analyses of supplementary outcomes such as predictions of disease outcomes with mRio score, NNT and NEDA assessments. In addition, teriflunomide has a well-characterized and favorable long-term safety profile that has been established with up to 12 years of exposure. Together, efficacy and safety data from clinical trials and real-world outcomes support the use of teriflunomide in the treatment of patients with relapsing forms of MS.

\section{Financial \& competing interests disclosure}

AE Miller: Consulting fees (Accordant Health Services, Acorda Therapeutics, Alkermes, Biogen Idec, EMD Serono, Genentech/Roche, Genzyme, GSK, Mallinckrodt Pharmaceuticals [Questcor], Novartis, and Teva); contracted research (Biogen Idec, Genentech/Roche, Novartis, Mallinckrodt Pharmaceuticals [Questcor], and Sanofi). The author has no other relevant affliations or financial involvement with any organization or entity with a financial interest in or financial conflict with the subject matter or materials discussed in the manuscript apart from those disclosed.

Editorial support (assistance in drafting and editing of the manuscript text, figures and tables, as directed by the author, data checking and incorporation of comments from reviewers, and assisting with the submission process) was provided by Kathryn Clausen of Fishawack Communications Ltd, funded by Sanofi Genzyme.

\section{References}

Papers of special note have been highlighted as: - of interest; $\bullet \bullet$ of considerable interest

1 Gold R, Wolinsky JS. Pathophysiology of multiple sclerosis and the place of teriflunomide. Acta Neurol. Scand. 124(2), 75-84 (2011).

2 Compston A, Coles A. Multiple sclerosis. Lancet 372 (9648), 1502-1517 (2008).

3 Bermel R, Bakshi R. The measurement and clinical relevance of brain atrophy in multiple sclerosis. Lancet Neurol. 5(2), 158-170 (2006).
4 Tremlett H, Yousefi M, Devonshire V, Rieckmann P, Zhao Y. Impact of multiple sclerosis relapses on progression diminishes with time. Neurology 73(20), 1616-1623 (2009).

5 Stangel M, Penner IK, Kallmann BA, Lukas C, Kieseier BC. Towards the implementation of 'no evidence of disease activity' in multiple sclerosis treatment: the multiple sclerosis decision model. Ther. Adv. Neurol. Disord. 8(1), 3-13 (2015).

6 Goodin DS. Disease-modifying therapy in multiple sclerosis: update and clinical implications. Neurology 71(24 Suppl. 3), S8-S13 (2008).

7 Sormani MP, Rio J, Tintore M et al. Scoring treatment response in patients with relapsing multiple sclerosis. Mult. Scler. 19(5), 605-612 (2013).

8 Jongen PJ, Lehnick D, Sanders E et al. Health-related quality of life in relapsing remitting multiple sclerosis patients during treatment with glatiramer acetate: a prospective, observational, international, multi-centre study. Health Qual. Life Outcomes 8, 133 (2010). 
9 Popescu V, Agosta F, Hulst HE et al. Brain atrophy and lesion load predict long term disability in multiple sclerosis. J. Neurol. Neurosurg. Psychiatry 84(10), 1082-1091 (2013).

$10 \quad$ PRISMS study group. Randomised double-blind placebo-controlled study of interferon beta-1a in relapsing/remitting multiple sclerosis. Lancet 352(9139), 1498-1504 (1998).

11 Group TIMSS. Interferon beta- $1 \mathrm{~b}$ is effective in relapsing-remitting multiple sclerosis. I. Clinical results of a multicenter, randomized, double-blind, placebo-controlled trial. The IFNB Multiple Sclerosis Study Group. Neurology 43(4), 655-661 (1993).

12 Johnson KP, Brooks BR, Cohen JA et al. Copolymer 1 reduces relapse rate and improves disability in relapsing-remitting multiple sclerosis: results of a Phase III multicenter, double-blind placebo-controlled trial. The Copolymer 1 Multiple Sclerosis Study Group. Neurology 45(7), 1268-1276 (1995).

13 Comi G, Filippi M, Wolinsky JS. European/Canadian multicenter, doubleblind, randomized, placebo-controlled study of the effects of glatiramer acetate on magnetic resonance imaging-measured disease activity and burden in patients with relapsing multiple sclerosis. European/ Canadian Glatiramer Acetate Study Group. Ann. Neurol. 49(3), 290-297 (2001).

14 Jacobs LD, Beck RW, Simon JH et al. Intramuscular interferon beta-1a therapy initiated during a first demyelinating event in multiple sclerosis. CHAMPS Study Group. N. Engl. J. Med. 343(13), 898-904 (2000).

15 Comi G, Filippi M, Barkhof F et al. Effect of early interferon treatment on conversion to definite multiple sclerosis: a randomised study. Lancet 357(9268), 1576-1582 (2001).

16 Comi G, Martinelli V, Rodegher $M$ et al. Effect of glatiramer acetate on conversion to clinically definite multiple sclerosis in patients with clinically isolated syndrome (PreCISe study): a randomised, double-blind, placebo-controlled trial. Lancet 374(9700), 1503-1511 (2009).

17 Kim W, Zandona ME, Kim SH, Kim HJ. Oral disease-modifying therapies for multiple sclerosis. J. Clin. Neurol. 11(1), 9-19 (2015).

18 Reuss R. PEGylated interferon beta-1a in the treatment of multiple sclerosis - an update. Biologics 7, 131-138 (2013).

19 Teva. Copaxone $40 \mathrm{mg} / \mathrm{ml}$ Solution for Injection, Summary of Product Characteristics. www.medicines.org.uk/emc/medicine/30795
20 Teva. Copaxone US Prescribing Information. www.copaxone.com/Resources/pdfs

21 Cohen JA, Barkhof F, Comi G et al. Oral fingolimod or intramuscular interferon for relapsing multiple sclerosis. $N$. Engl. J. Med. 362(5), 402-415 (2010).

22 Kappos L, Radue EW, O'Connor P et al. A placebo-controlled trial of oral fingolimod in relapsing multiple sclerosis. N. Engl. J. Med. 362(5), 387-401 (2010).

23 Calabresi PA, Radue EW, Goodin D et al. Safety and efficacy of fingolimod in patients with relapsing-remitting multiple sclerosis (FREEDOMS II): a double-blind, randomised, placebo-controlled, Phase 3 trial. Lancet Neurol. 13(6), 545-556 (2014).

24 Novartis. Gilenya US Prescribing Information. www.pharma.us.novartis.com/product/pi

25 Novartis. Gilenya Information Center. www.novartis.com/news/statements

26 Brooks M. Third Case of PML With Fingolimod (Gilenya) in MS. www.medscape.com/viewarticle/849677

27 Cree B. Risk stratification and mitigation. Presented at: 68th American Academy of Neurology Annual Meeting. Vancouver, BC, Canada, 15-21 April 2016.

28 Fox R. Treatment options: weighing risks and benefits. Presented at: 68th American Academy of Neurology Annual Meeting. Vancouver, BC, Canada, 15-21 April 2016.

29 Scannevin RH, Chollate S, Jung MY et al. Fumarates promote cytoprotection of central nervous system cells against oxidative stress via the nuclear factor (erythroid-derived 2)-like 2 pathway. J. Pharmacol. Exp. Ther. 341(1), 274-284 (2012).

30 Fox RJ, Miller DH, Phillips JT et al. Placebo-controlled Phase 3 study of oral BG-12 or glatiramer in multiple sclerosis. N. Engl. J. Med. 367(12), 1087-1097 (2012).

31 Gold R, Kappos L, Arnold DL et al. Placebo-controlled Phase 3 study of oral BG-12 for relapsing multiple sclerosis. N. Engl. J. Med. 367(12), 1098-1107 (2012).

32 Biogen, Inc. Tecfidera US Prescribing Information. www.tecfidera.com/pdfs/full-prescribing

33 Fiore K. Will 4th PML Case Change Tecfidera Risk Profile? www.medpagetoday.com/neurology

34 Biogen, TYSABRI ${ }^{\circledR}$ (natalizumab): PML in Patients Receiving TYSABRI. https://medinfo.biogen.com/secure/download

35 Chigaev A, Wu Y, Williams DB, Smagley Y, Sklar LA. Discovery of very late antigen-4 (VLA-4, alpha4beta1 integrin) allosteric antagonists. J. Biol. Chem. 286(7), 5455-5463 (2011).

36 Polman CH, O'Connor PW, Havrdova E et al. A randomized, placebo-controlled trial of natalizumab for relapsing multiple sclerosis. N. Engl. J. Med. 354(9), 899-910 (2006).

37 Biogen, Tysabri (natalizumab) Product Monograph. www.biogen.ca/content/dam/corporate

38 Genzyme. Lemtrada US Prescribing Information.

http://products.sanofi.us/lemtrada/lemtrada

39 Havrdova E, Horakova D, Kovarova I. Alemtuzumab in the treatment of multiple sclerosis: key clinical trial results and considerations for use. Ther. Adv. Neurol. Disord. 8(1), 31-45 (2015).

40 Wiendl H, Kieseier B. Reprogramming the immune repertoire with alemtuzumab in MS. Nat. Rev. Neurol. 9(3), 125-126 (2013).

41 Cohen JA, Coles AJ, Arnold DL et al. Alemtuzumab versus interferon beta $1 \mathrm{a}$ as first-line treatment for patients with relapsing-remitting multiple sclerosis: a randomised controlled Phase 3 trial. Lancet 380 (9856), 1819-1828 (2012).

42 Coles AJ, Twyman CL, Arnold DL et al. Alemtuzumab for patients with relapsing multiple sclerosis after disease-modifying therapy: a randomised controlled Phase 3 trial. Lancet 380 (9856), 1829-1839 (2012).

43 Arnold DLT, Coles A, Cohen AJ et al. Durable effect of alemtuzumab on MRI activity in treatment-naive active relapsingremitting multiple sclerosis patients: 4-year follow-up of CARE-MS I. Presented at: 67th American Academy of Neurology Annual Meeting. Washington, DC, USA,18-25 April 2015.

44 Traboulsee AC, Cohen AJ, Compston JA et al. Durable effect of alemtuzumab on MRI outcomes in patients with relapsing-remitting multiple sclerosis who relapsed on prior therapy: 4-year follow-up of CARE-MS II. Presented at: 67th American Academy of Neurology Annual Meeting. Washington, DC, USA, 18-25 April 2015.

45 Biogen. Zinbryta (daclizumab) US Prescribing Information.

www.zinbryta.com/content/dam

46 Gold R, Giovannoni G, Selmaj K et al. Daclizumab high-yield process in relapsingremitting multiple sclerosis (SELECT): a randomised, double-blind, placebocontrolled trial. Lancet 381(9884), 2167-2175 (2013).

47 Kappos L, Wiendl H, Selmaj K et al. Daclizumab HYP versus interferon beta-1a in 
relapsing multiple sclerosis. N. Engl. J. Med. 373(15), 1418-1428 (2015).

48 Genzyme. Aubagio US Product Information. http://products.sanofi.us/aubagio/aubagio

49 Genzyme. Aubagio Summary of Product Characteristics.

www.ema.europa.eu/docs/en_GB

50 O'Connor PW, Li D, Freedman MS et al. A Phase II study of the safety and efficacy of teriflunomide in multiple sclerosis with relapses. Neurology 66(6), 894-900 (2006).

51 O'Connor P, Wolinsky JS, Confavreux C et al. Randomized trial of oral teriflunomide for relapsing multiple sclerosis. $N$. Engl. J. Med. 365(14), 1293-1303 (2011).

-. TEMSO was a randomized, double-blind, placebo-controlled Phase III trial of teriflunomide in patients with relapsing forms of multiple sclerosis (MS). Teriflunomide had positive effects on annualized relapse rate, risk of disability worsening and several MRI outcomes.

52 Confavreux C, O'Connor P, Comi G et al. Oral teriflunomide for patients with relapsing multiple sclerosis (TOWER): a randomised, double-blind, placebocontrolled, Phase 3 trial. Lancet Neurol. 13(3), 247-256 (2014).

- TOWER was a randomized, double-blind, placebo-controlled Phase III trial of teriflunomide in patients with relapsing MS. Teriflunomide treatment significantly reduced annualized relapse rate and risk of disability worsening. MRI outcomes were not assessed in TOWER.

53 Miller AE, Wolinsky JS, Kappos L et al. Oral teriflunomide for patients with a first clinical episode suggestive of multiple sclerosis (TOPIC): a randomised, double-blind, placebo-controlled, Phase 3 trial. Lancet Neurol. 13(10), 977-986 (2014).

-• TOPIC was a randomized, double-blind, placebo-controlled Phase III clinical trial in patients with a first clinical episode suggestive of MS. In this first study of teriflunomide in patients with early MS, teriflunomide significantly reduced the time to relapse confirming clinically definite MS, compared with placebo.

54 Confavreux C, Li DK, Freedman MS et al. Long-term follow-up of a Phase 2 study of oral teriflunomide in relapsing multiple sclerosis: safety and efficacy results up to 8.5 years. Mult. Scler. 18(9), 1278-1289 (2012).

55 O'Connor PW, Comi G, Freedman MS et al. Long-term safety and efficacy of teriflunomide: 9 years' follow-up of the randomized TEMSO study. Neurology 86(10), 920-930 (2016).

56 Freedman MS, Kappos L, Comi G et al. Long-term safety of teriflunomide: 2.5-year follow-up in the TOWER extension study in patients with relapsing MS. Presented at: 31st Congress of the European Committee for Treatment and Research in Multiple Sclerosis. Barcelona, Spain, 7-10 October 2015.

57 Sanofi. Arava US Product Information. http://products.sanofi.us/arava/arava.html

58 Bar-Or A, Pachner A, Menguy-Vacheron F, Kaplan J, Wiendl H. Teriflunomide and its mechanism of action in multiple sclerosis. Drugs 74(6), 659-674 (2014).

59 Sanofi-Aventis. Aubagio EU Summary of Product Characteristics. www.ema.europa.eu/docs/en_GB

60 Wiendl H, Gross CC, Lindner M et al. Characterizing the impact of teriflunomide on adaptive immune cell subsets, repertoire and function in patients with relapsingremitting MS: TERI-DYNAMIC. Presented at: 31st Congress of the European Committee for Treatment and Research in Multiple Sclerosis. Barcelona, Spain, 7-10 October 2015.

61 Limsakun, Menguy-Vacheron TF. Pharmacokinetics of oral teriflunomide, a novel oral disease-modifying agent under investigation for the treatment of multiple sclerosis. Presented at: 62nd American Academy of Neurology Annual Meeting. Toronto, Ontario, 10-17 April 2010.

62 Kremenchutzky M, Freedman MS, Bar-Or A et al. 12-year clinical efficacy and safety data for teriflunomide: results from a Phase 2 extension study. Presented at: 67th American Academy of Neurology Annual Meeting. Washington, DC, USA, 18-25 April 2015.

63 Miller AE, O'Connor P, Wolinsky JS et al. Pre-specified subgroup analyses of a placebocontrolled Phase III trial (TEMSO) of oral teriflunomide in relapsing multiple sclerosis. Mult. Scler. 18(11), 1625-1632 (2012).

64 Vermersch P, Czlonkowska A, Grimaldi LM et al. Teriflunomide versus subcutaneous interferon beta-1a in patients with relapsing multiple sclerosis: a randomised, controlled Phase 3 trial. Mult. Scler. 20(6), 705-716 (2014).

- TENERE was a rater-blinded Phase III study, in which the efficacy of teriflunomide was compared with that of subcutaneous IFNB-1a in patients with relapsing forms of MS. The primary composite end point, the rate of relapse or treatment discontinuation, was not significantly different across the teriflunomide and IFNB-1a treatment groups.
65 Radue E, Sprenger T, Gaetano L et al. Teriflunomide slows down brain volume loss in relapsing MS: a SIENA analysis of the TEMSO MRI dataset. Presented at: 31st Congress of the European Committee for Treatment and Research in Multiple Sclerosis. Barcelona, Spain, 7-10 October 2015.

66 O'Connor PW, Lublin FD, Wolinsky JS et al. Teriflunomide reduces relapse-related neurological sequelae, hospitalizations and steroid use. J. Neurol. 260 (10), 2472-2480 (2013).

67 Kappos L, Freedman MS, Comi G et al. Teriflunomide efficacy on annualized relapse rate and expanded disability status scores: 2.5-year follow-up in the TOWER extension study in patients with relapsing MS. Presented at: 31st Congress of the European Committee for Treatment and Research in Multiple Sclerosis. Barcelona, Spain, 7-10 October 2015.

68 O'Connor PW, Wolinsky JS, Thangavelu K, Truffinet P, Rufi P, Kappos L. Reduced risk of disability progression in patients with MS treated with early vs delayed teriflunomide $14 \mathrm{mg}$. Presented at: 31 st Congress of the European Committee for Treatment and Research in Multiple Sclerosis. Barcelona, Spain, 7-10 October 2015.

69 Polman $\mathrm{CH}$, Reingold SC, Banwell B et al. Diagnostic criteria for multiple sclerosis: 2010 revisions to the McDonald criteria. Ann. Neurol. 69(2), 292-302 (2011).

70 de Seze J, Olsson T, Czlonkowska A et al. Safety and efficacy of teriflunomide in patients switching from subcutaneous interferon beta-1a. Presented at: 67th American Academy of Neurology Annual Meeting. Washington, DC, USA, 18-25 April 2015.

71 Bar-Or A, Freedman MS, Kremenchutzky M et al. Teriflunomide effect on immune response to influenza vaccine in patients with multiple sclerosis. Neurology 81(6), 552-558 (2013).

- In this vaccination study, healthy subjects receiving teriflunomide were able to mount an effective immune response to neoantigen challenge (rabies vaccine).

72 Bar-Or A, Larouche R, Legrand B et al. Immune response to neoantigen and recall antigens in healthy subjects receiving teriflunomide. Mult. Scler. 19(S1), 74-558. P622 (2013).

- Demonstrates that a stable dose of teriflunomide did not adversely affect the ability of patients with relapsing forms of MS to mount a successful immune response to a recall antigen (influenza vaccine).

73 Laupacis A, Sackett DL, Roberts RS. An assessment of clinically useful measures of the 
consequences of treatment. N. Engl. J. Med. 318(26), 1728-1733 (1988).

74 Collins R, Peto R, MacMahon S et al. Blood pressure, stroke, and coronary heart disease. II. Short-term reductions in blood pressure: overview of randomized drug trials in their epidemiologic context. Lancet 335(8697), 827-838 (1990).

75 Leist T, Freedman M, Miller A, Dive-Pouletty C, Montalban X. Assessing comparative outcomes from teriflunomide and dimethyl fumarate studies in relapsing MS: use of "number needed to treat" analysis. Neurology 84(14), Supplement P3.245 (2015).

76 Chan A, de Seze J, Truffinet P, Thangavelu K, Rufi P, Comabella M. Significant efficacy of teriflunomide in TEMSO study using "no evidence of disease activity" (NEDA) as a composite end point. Presented at: 88th Congress of the Deutschen Gesellschaft für Neurologie. Düsseldorf, Germany, 23-26 September 2015.

77 Chan A, de Seze J, Truffinet P, Thangavelu K, Rufi P, Comabella M. Efficacy of teriflunomide treatment in achieving no evidence of disease activity over a period of 6 months to 2 years in the TEMSO study. Presented at: 31 st Congress of the European Committee for Treatment and Research in Multiple Sclerosis. Barcelona, Spain, 7-10 October 2015.

78 Wolinsky JS, Freedman MS, Thangavelu K, Truffinet P, Rufi P, O'Connor PW. Efficacy of teriflunomide treatment in achieving no evidence of disease activity in the TEMSO long-term extension study. Presented at: 31st Congress of the European Committee for Treatment and Research in Multiple Sclerosis. Barcelona, Spain, 7-10 October 2015.

79 Sormani MP, Thangavelu K, Rufi P, DeStefano N. Predicting treatment response to teriflunomide in the TEMSO study using the modified Rio score. Presented at: 31st Congress of the European Committee for Treatment and Research in Multiple Sclerosis Barcelona, Spain, 7-10 October 2015.
80 Coyle PK, LaGanke C, Khatri B et al. Improvements in patient-reported outcomes with teriflunomide: week 24 interim results from the US cohort of the Teri-PRO Phase 4 study. Presented at: 31st Congress of the European Committee for Treatment and Research in Multiple Sclerosis. Barcelona, Spain, 7-10 October 2015.

81 Gold R, Coyle PK, LaGanke C et al. Treatment satisfaction with teriflunomide: preliminary results at Week 4 for patients from Canada, Europe, and Latin America enrolled in the Teri-PRO Phase 4 study. Presented at: 1st Congress of the European Academy of Neurology. Berlin, Germany, 20-23 June 2015.

82 Edwards K, Freedman MS. Safety and efficacy of transitioning to teriflunomide in patients switching from other disease-modifying therapies, including natalizumab. Presented at: 31st Congress of the European Committee for Treatment and Research in Multiple Sclerosis. Barcelona, Spain, 7-10 October 2015.

83 Comi G, Freedman MS, Kappos L et al. Pooled safety and tolerability data from four placebocontrolled teriflunomide studies and extensions. Mult. Scler. Rel. Disord. 5, 97-104 (2016).

- This analysis of pooled data from the teriflunomide clinical trial database supports the well-characterized, manageable safety and tolerability profile of teriflunomide that was observed in the individual studies.

84 Edwards KR, Hendin Travis L, Okai A et al. Hair photography project: exploring the clinical course of hair thinning associated with teriflunomide. Presented at: 31st Congress of the European Committee for Treatment and Research in Multiple Sclerosis. Barcelona, Spain, 7-10 October 2015.

85 Freedman M, Confavreux C, Comi C. Hair thinning associated with teriflunomide therapy is manageable. Presented at: 4 th Cooperative Meeting of CMSC and ACTRIMS. San Diego, CA, USA, 30 May-2 June 2012.
86 Hendin Travis L, Okai A, Jackson S et al. Exploring the clinical course of hair thinning associated with teriflunomide: an update to the teriflunomide real-world case series. 31st Congress of the European Committee for Treatment and Research in Multiple Sclerosis. Barcelona, Spain, 7-10 October 2015.

87 Chambers CD, Johnson DL, Robinson LK et al. Birth outcomes in women who have taken leflunomide during pregnancy. Arthritis Rheum. 62(5), 1494-1503 (2010).

88 Rådet for Anvendelse af Dyr Sygehusmedicin, (RADS; The Danish Council for the Use of Expensive Hospital Medicine). RADS Treatment guidelines including recommended medicines for disease modifying treatment of multiple sclerosis.

www.regioner.dk/media/1900/beh-inklusiv

89 Kieseier BC, Benamor M. Pregnancy outcomes following maternal and paternal exposure to teriflunomide during treatment for relapsing-remitting multiple sclerosis. Neurol. Ther. 3(2), 133-138 (2014).

- In this retrospective analysis of outcomes from pregnancies that occurred in the teriflunomide clinical trial program, it was reported that no structural or functional abnormalities were noted at birth for babies born to patients exposed to teriflunomide.

90 Garcia-Enguidanos A, Calle ME, Valero J, Luna S, Dominguez-Rojas V. Risk factors in miscarriage: a review. Eur. J. Obstet. Gynecol. Reprod. Biol. 102(2), 111-119 (2002).

91 OTIS. MotherToBaby - Autoimmune Disease. http://mothertobaby.org/autoimmune

92 Hellwig K, Lebrun-Frenay C, Rog D et al. Teriflunomide (Aubagio) pregnancy registry: design and enrolment procedures for pregnant women with multiple sclerosis exposed to teriflunomide. Presented at: 1st Congress of the European Academy of Neurology. Berlin, Germany, 20-23 June 2015. 